\title{
Preliminary Test Results In Support Of Integrated EPP and SMT Design Methods Development
}

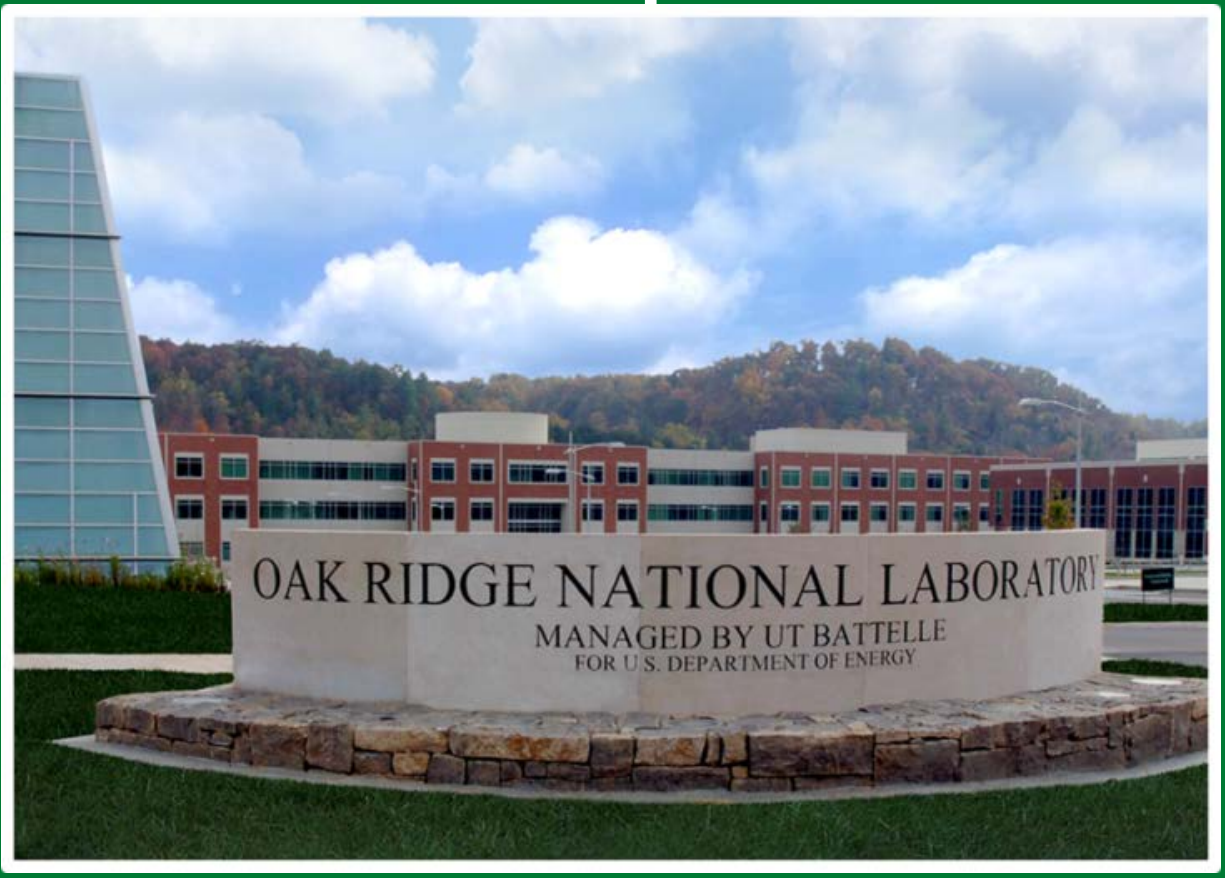

Approved for public release. Distribution is unlimited.
Yanli Wang

Robert I. Jetter

T.-L. Sham

February 29, 2016 


\title{
DOCUMENT AVAILABILITY
}

Reports produced after January 1, 1996, are generally available free via US Department of Energy (DOE) SciTech Connect.

\section{Website http://www.osti.gov/scitech/}

Reports produced before January 1, 1996, may be purchased by members of the public from the following source:

\author{
National Technical Information Service \\ 5285 Port Royal Road \\ Springfield, VA 22161 \\ Telephone 703-605-6000 (1-800-553-6847) \\ TDD 703-487-4639 \\ Fax 703-605-6900 \\ E-mail info@ntis.gov \\ Website http://www.ntis.gov/help/ordermethods.aspx
}

Reports are available to DOE employees, DOE contractors, Energy Technology Data Exchange representatives, and International Nuclear Information System representatives from the following source:

Office of Scientific and Technical Information

PO Box 62

Oak Ridge, TN 37831

Telephone 865-576-8401

Fax 865-576-5728

E-mail reports@osti.gov

Website http://www.osti.gov/contact.html

This report was prepared as an account of work sponsored by an agency of the United States Government. Neither the United States Government nor any agency thereof, nor any of their employees, makes any warranty, express or implied, or assumes any legal liability or responsibility for the accuracy, completeness, or usefulness of any information, apparatus, product, or process disclosed, or represents that its use would not infringe privately owned rights. Reference herein to any specific commercial product, process, or service by trade name, trademark, manufacturer, or otherwise, does not necessarily constitute or imply its endorsement, recommendation, or favoring by the United States Government or any agency thereof. The views and opinions of authors expressed herein do not necessarily state or reflect those of the United States Government or any agency thereof. 
Materials Science and Technology Division

\title{
PRELIMINARY TEST RESULTS IN SUPPORT OF INTEGRATED EPP AND SMT DESIGN METHODS DEVELOPMENT
}

\author{
Yanli Wang, Robert I. Jetter* and T.-L. Sham $†$
}

* Consultant

†Argonne National Laboratory

Date Published: February 29, 2016

Prepared by OAK RIDGE NATIONAL LABORATORY

Oak Ridge, TN 37831-6283

managed by

UT-BATTELLE, LLC

for the

US DEPARTMENT OF ENERGY

under contract DE-AC05-00OR22725 



\section{CONTENTS}

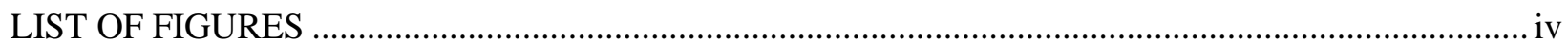

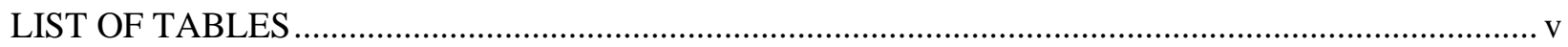

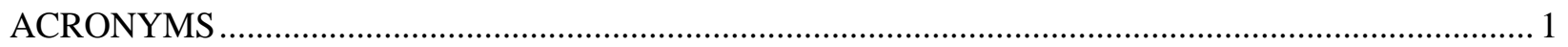

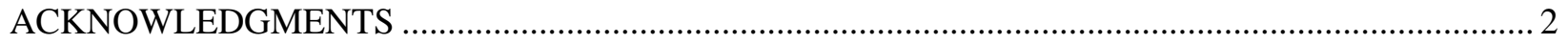

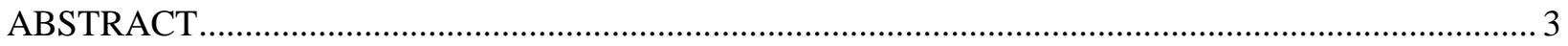

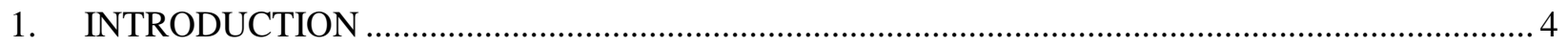

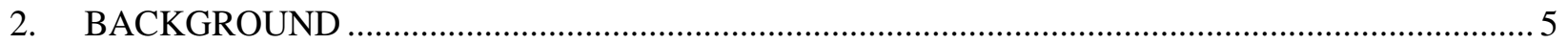

2.1 EPP ANALYSIS AND INTEGRATED CREEP-FATIGUE DAMAGE …........................... 5

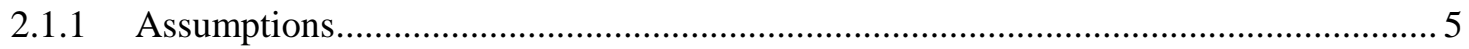

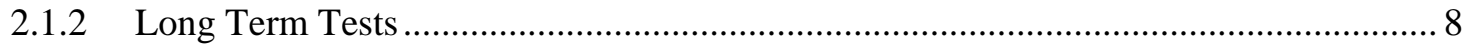

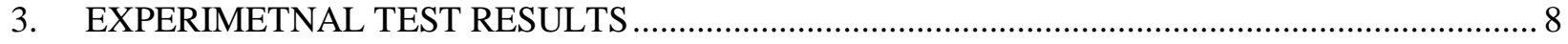

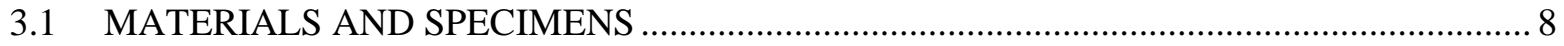

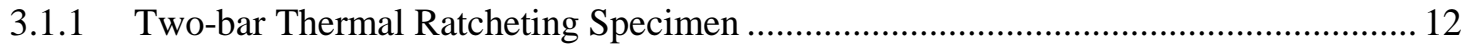

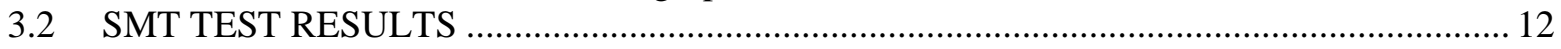

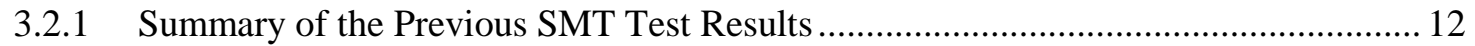

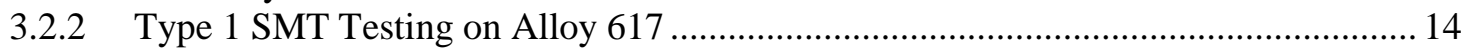

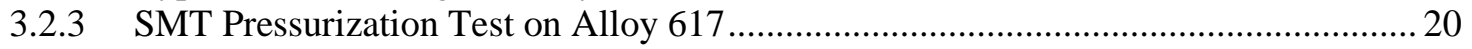

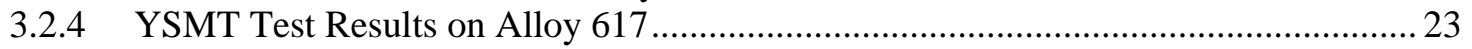

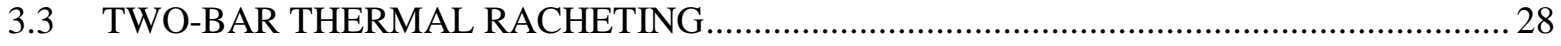

3.3.1 Previous Two-bar Thermal Ratcheting Test Results ................................................. 28

3.3.2 Two-bar Thermal Ratcheting of SS316H at Temperature Range of $250^{\circ} \mathrm{C}$ to 550

${ }^{\circ} \mathrm{C}$

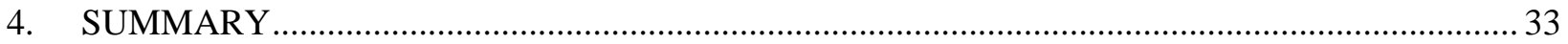

4.1 Lower Temperature Test Results ......................................................................................... 33

4.2 Compression Hold or Combined Tensile-Compression Hold Tests for Type 1 SMT

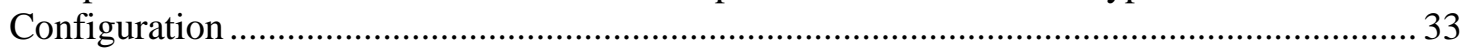

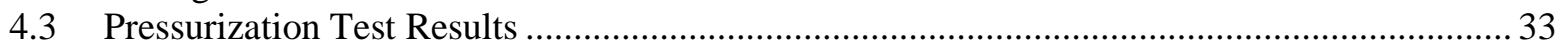

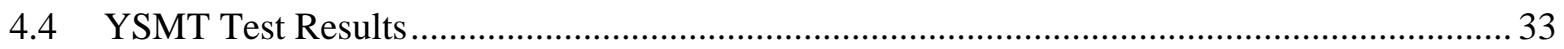

4.5 Two-bar Thermal Ratcheting of SS316H at Temperature Range of $250^{\circ} \mathrm{C}$ to $550{ }^{\circ} \mathrm{C} \ldots \ldots \ldots \ldots . . . .34$

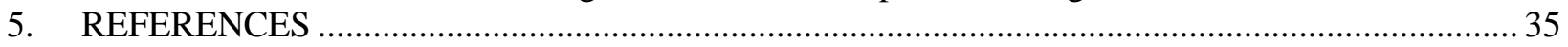




\section{LIST OF FIGURES}

Fig. 1. Path to resolution and verification of the EPP-SMT approach............................................... 6

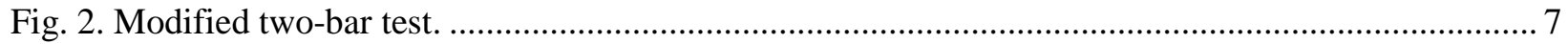

Fig. 3. Type 1 SMT solid bar specimen geometry. Units are in inches. ............................................... 9

Fig. 4. Type 2 SMT solid bar specimen geometry. Units are in inches.................................................. 10

Fig. 5. SMT pressurization specimen geometry with adaptor for Alloy 617. Units are in inches............. 11

Fig. 6. YSMT specimen geometry. Units are in inches. .................................................................. 12

Fig. 7. Specimen geometry of Alloy 617 and SS316H used in two-bar thermal ratcheting

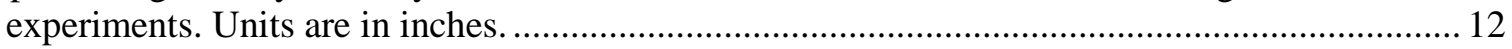

Fig. 8. Applied end-displacement profile for one cycle of creep-fatigue testing with tension hold........... 13

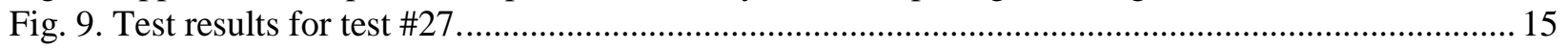

Fig. 10. Applied end-displacement profile for one cycle of creep-fatigue testing with compression

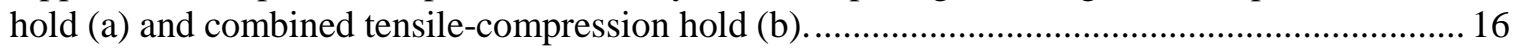

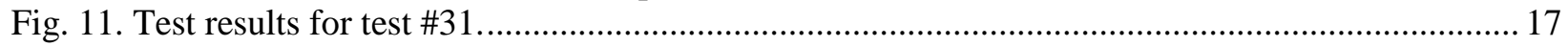

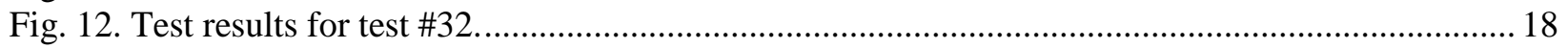

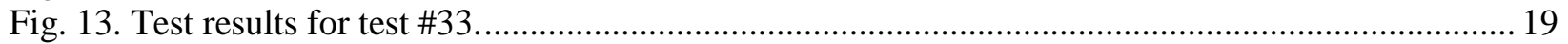

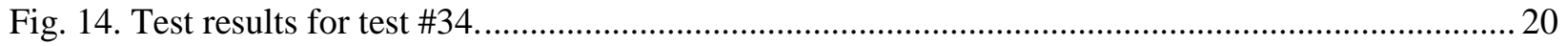

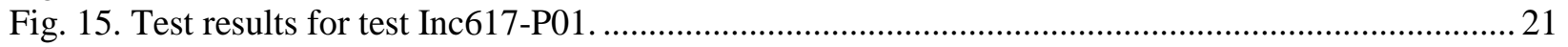

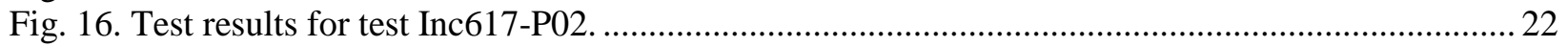

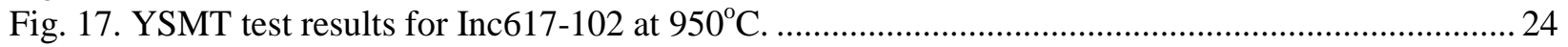

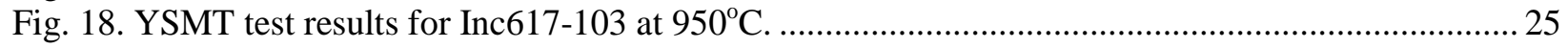

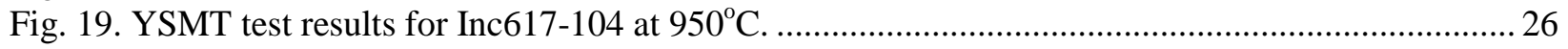

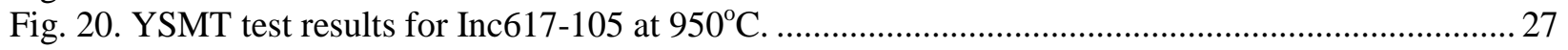

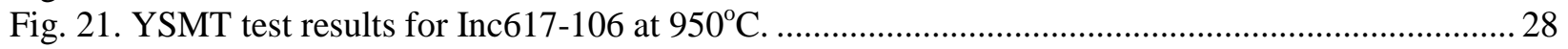

Fig. 22. Temperature vs. time histogram for two-bar thermal ratcheting experiments.............................. 29

Fig. 23. Two bar test data with $1 \%$ design envelope predictions from the strain limits code case and inelastic analysis (Alloy 617 with testing temperature range of $650^{\circ} \mathrm{C}$ to $950^{\circ} \mathrm{C}$ ). ............... 29

Fig. 24. Two bar test data with $1 \%$ design envelope predictions from the strain limits code case

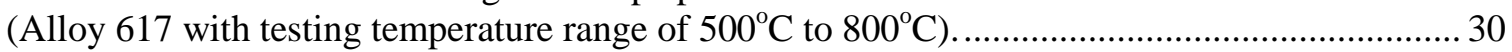

Fig. 25. Two bar test data with $1 \%$ design envelope predictions from the strain limits code case

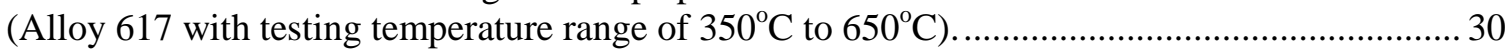

Fig. 26. Two bar test data with $1 \%$ design envelope predictions from the strain limits code case and inelastic analysis (SS316 H with testing temperature range of $515^{\circ} \mathrm{C}$ to $815^{\circ} \mathrm{C}$ )................... 31

Fig. 27. Two bar test data for SS316H with testing temperature range of $250-550^{\circ} \mathrm{C} \ldots \ldots \ldots \ldots \ldots \ldots \ldots \ldots \ldots . . . . . . . . . . . . . . .32$ 


\section{LIST OF TABLES}

Table 1. Chemical compositions of Alloy 617 plate with heat number 314626 (weight \%)....................... 8

Table 2. Chemical compositions of SS316H bar with heat number 101076 (weight \%). .......................... 8

Table 3. Chemical compositions of SS304H bar with heat number E131181 (weight \%).......................... 8

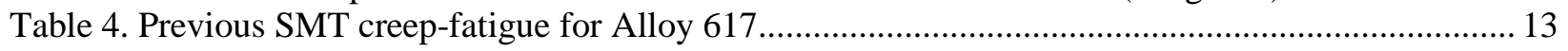

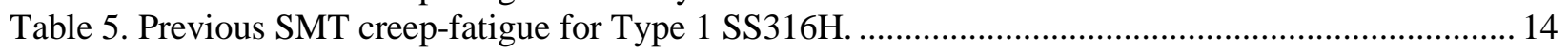

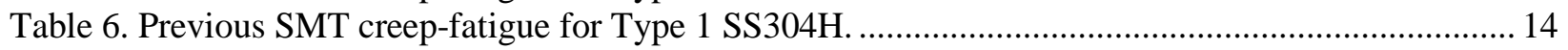

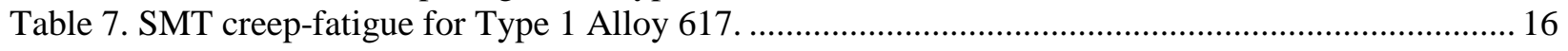

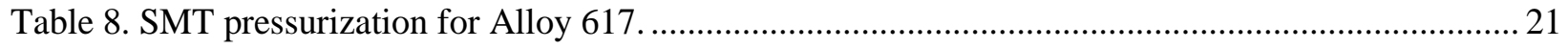

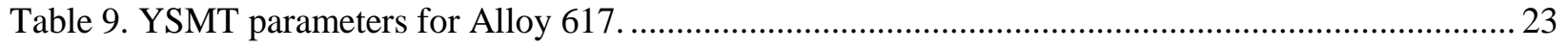

Table 10. YSMT results for Alloy 617 ............................................................................................. 23

Table 11. Summary of the two-bar thermal ratcheting experiments on SS316H for temperature

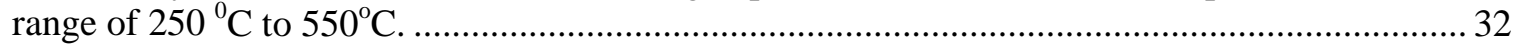




\section{ACRONYMS}

ASME American Society of Mechanical Engineers

DOE Department of Energy

EPP Elastic-Perfectly Plastic

ORNL Oak Ridge National Laboratory

SMT Simplified Module Test 


\section{ACKNOWLEDGMENTS}

This research was sponsored by the U.S. Department of Energy (DOE), Office of Nuclear Energy (NE), Advanced Reactor Technologies (ART) Program. We gratefully acknowledge the support provided by Carl Sink of DOE-NE, Advanced Reactor Technologies, ART Program Manager; William Corwin of DOE-NE, ART Materials Technology Lead; David Petti of Idaho National Laboratory (INL), ART CoNational Technical Director; and Richard Wright of INL, Technical Lead, High Temperature Materials.

Helpful discussion with Peter Carter of Stress Engineering Services, Inc. is gratefully acknowledged. Donald Erdman of Oak Ridge National Laboratory (ORNL) programmed the controls. Technical support from Jeremy Moser, David Thomas and Shane Hawkins of ORNL is greatly appreciated. The time spent by Hong Wang and Edgar Lara-Curzio of ORNL in reviewing this report is greatly appreciated.

We would also like to acknowledge Richard Wright for supplying the Alloy 617 materials to support the testing task of this work. 


\begin{abstract}
The proposed integrated Elastic Perfectly-Plastic (EPP) and Simplified Model Test (SMT) methodology consists of incorporating a SMT data-based approach for creep-fatigue damage evaluation into the EPP methodology to avoid using the creep-fatigue interaction diagram (the D diagram) and to minimize overconservatism while properly accounting for localized defects and stress risers. To support the implementation of the proposed code rules and to verify their applicability, a series of thermomechanical tests have been initiated. One test concept, the Simplified Model Test (SMT), takes into account the stress and strain redistribution in real structures by including representative follow-up characteristics in the test specimen. The second test concept is the two-bar thermal ratcheting tests with cyclic loading at high temperatures using specimens representing key features of potential component designs.

This report summaries the previous SMT results on Alloy 617, SS316H and SS304H and presents the recent development on SMT approach on Alloy 617. These SMT specimen data are also representative of component loading conditions and have been used as part of the verification of the proposed integrated EPP and SMT design methods development. The previous two-bar thermal ratcheting test results on Alloy 617 and SS316H are also summarized and the new results from two bar thermal ratcheting tests on SS316H at a lower temperature range are reported.
\end{abstract}




\section{INTRODUCTION}

The goal of the EPP-SMT approach is to incorporate a SMT data based approach for creep-fatigue damage evaluation into the EPP methodology to avoid the use of the D diagram and to minimize overconservatism while properly accounting for localized defects and stress risers. Below the creep regime this approach is already accommodated in Subsection NB through plastic analysis per NB-3228.4 for primary plus secondary stress limits and cumulative fatigue damage based on the strain ranges from the EPP analysis. The challenge is to extend the concept to the creep regime through appropriately chosen pseudo stress values and shakedown analyses.

During this reporting period, on SMT method development, the concept of Elastic-Perfectly Plastic (EPP) combined integrated creep-fatigue damage evaluation approach is developed. A path forward to merge these methodologies was identified along with the anticipated problems, facilitating assumptions, and required steps and test data needed to verify their applicability. Experimentally, tests with SMT solid bar, SMT pressurization and YSMT were performed on Alloy 617 to support SMT design method development. SMT experiments were expanded to lower testing temperatures and loading profiles with compression-hold only and combined tension-compression hold. 


\section{BACKGROUND}

There are two approaches of interest to the proposed integrated evaluation of cyclic service life that have received attention over the last several years. One of these approaches is identified as the Elastic-Perfectly Plastic (EPP) methodology and the other is identified as the Simplified Model Test (SMT) methodology.

The EPP cyclic service code cases address both of those objectives in that they are applicable at very high temperatures and greatly simplify the design evaluation procedure by eliminating the need for stress classification that is the basis of the current rules. However, the EPP Code Case for evaluation of creepfatigue damage still requires the separate evaluation of creep damage and fatigue damage by placing a limit on the allowable combined damage, the " $\mathrm{D}$ " diagram based on the calculated individual damages. The difficulties and approximations in the D diagram approach are what led to the second approach of interest, the Simplified Model Test or SMT methodology.

The original SMT approach is based on the use of elastic analysis. The experimental data, number of cycles to failure, is correlated using the elastically calculated strain range in the test specimen and the corresponding component strain is also calculated elastically. The advantage of this approach is that it is no longer necessary to use the damage interaction, or $\mathrm{D}$, diagram because the damage due to the combined effects of creep and fatigue are accounted in the test data by means of a specimen that is designed to replicate or bound the stress and strain redistribution that occurs in actual components when loaded in the creep regime. However, as originally proposed, there is still a requirement for stress classification into primary, $\mathrm{P}$, primary plus secondary, $\mathrm{P}+\mathrm{Q}$, and primary plus secondary plus peak, $\mathrm{P}+$ $\mathrm{Q}+\mathrm{F}$, for the overall design procedure.

The goal of the EPP-SMT approach is to incorporate a SMT data based approach for creep-fatigue damage evaluation into the EPP methodology to avoid the use of the D diagram and to minimize overconservatism while properly accounting for localized defects and stress risers. Below the creep regime this approach has been already accommodated in Subsection NB through plastic analysis per NB-3228.4 for primary plus secondary stress limits and cumulative fatigue damage based on the strain ranges from the EPP analysis. The challenge is to extend the concept to the creep regime through appropriately chosen pseudo stress values and shakedown analyses

\subsection{EPP ANALYSIS AND INTEGRATED CREEP-FATIGUE DAMAGE}

Fig. 1 is a flow chart that identifies key issues, assumptions and the proposed path to resolution and verification of the EPP-SMT approach. The major elements in this flow chart include: three key assumptions that have been made to move forward; the near term test and evaluation actions required to validate these assumptions; and the long term test and analytical development required depending upon the outcome of the near term validation efforts.

\subsubsection{Assumptions}

\subsubsection{EPP-SMT approach will be based on the EPP/Strain limit code case with the pseudo yield stress based on the stress to $\mathrm{x} \%$ strain and shakedown to plastic cycling.}

The rationale is that the strain limit code case provides an upper bound to creep strain that can be used to approximate the creep strain per cycle by dividing by the number of cycles similar to the cyclic creep strain adjustment in Subsection HBB (formerly NH). (Note: it would be advantageous to be able to calculate a local creep strain instead of a bounding strain. Also, in the current methodology, the actual length of time in an over temperature transient isn't taken into account, thus overweighting the effect of short time over temperature transients.) 
An important initial consideration is whether the use of the SMT data for validation of the strain range methodology will be subject to the same limitations as the two bar test results. As described above, the two bar results were not in agreement with the EPP strain limit code case predictions. The so-called "stovepipe" plot of allowable temperature difference vs. applied mean load was predicted at much lower mean loads than the test data. This was postulated to be caused by uniform temperature and stress fields in the EPP model and it was demonstrated by inelastic analysis of a distributed load example, a Bree type cylinder, that the EPP strain limit methodology worked for representative distributed load geometries and temperatures. The concern is that if there is, unexpectedly, a similar situation with the EPP strain limit application to the SMT data, it is not clear how to proceed using that data as a basis for validation. As shown in Fig. 1 under the category of "Near term test and evaluation", what is needed is an EPP evaluation of the current and near term SMT data to confirm its applicability.

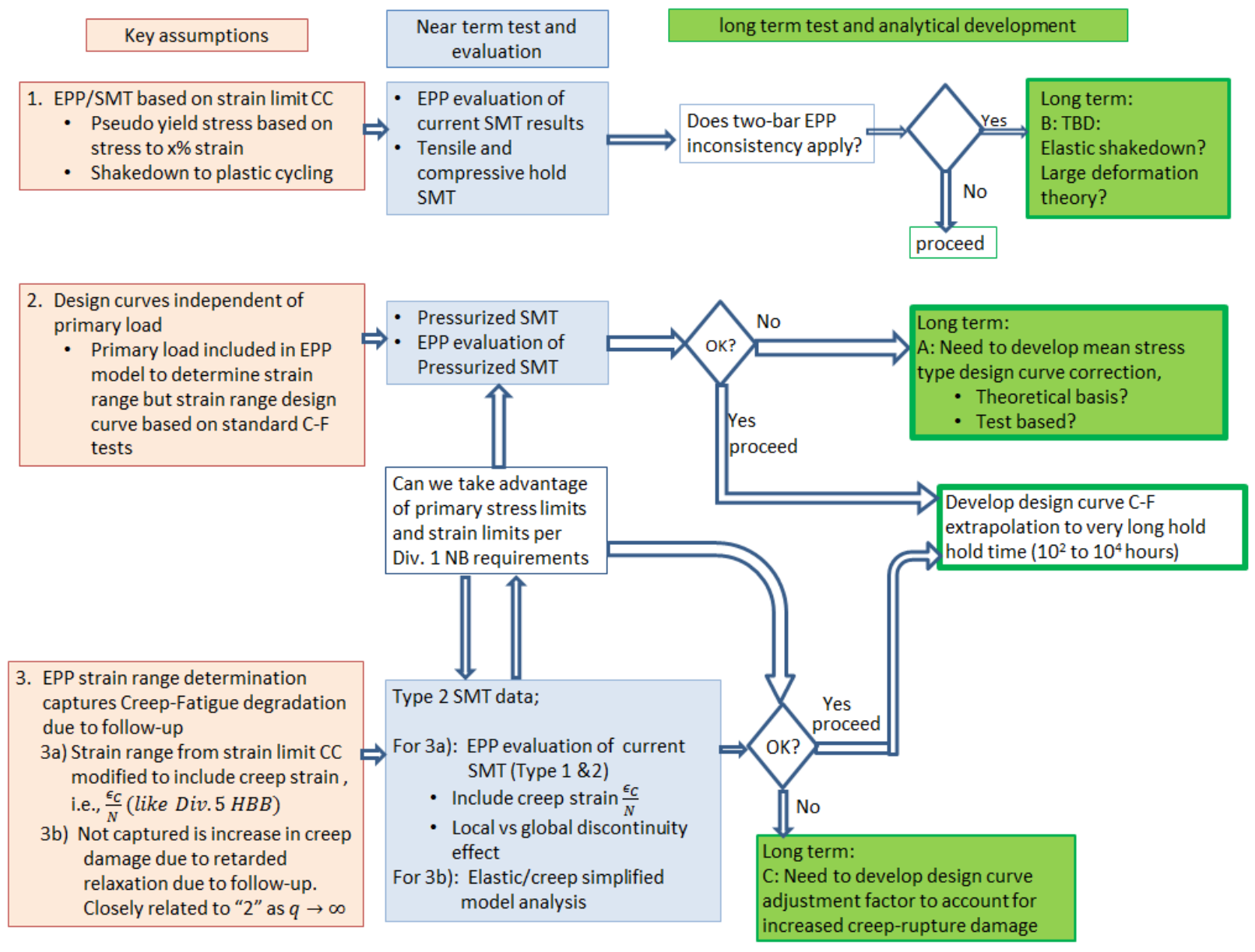

Fig. 1. Path to resolution and verification of the EPP-SMT approach.

Also shown under the category of "Near term test and evaluation”, is a comparison of tension hold data with data from tests with alternating tension and compression hold times. The reason for this is twofold. First, it would be desirable to base the validation on the more conservative data. However, perhaps the more important reason is to minimize the barreling effect that clouds the interpretation of the tension-hold only test data.

Also noted here, is the proposal to use standard creep-fatigue data as the basis for generation of the SMT type design curve. 


\subsubsection{The design curves will be independent of primary load.}

Part of the rationale for this is that the primary load is included in the EPP model to determine strain range. Also, as described in Jetter's original SMT paper (Jetter, 1998), the stress level associated with primary loading will be small compared with the secondary and peak stress levels and shouldn't have a significant effect on the total life. However, it is important to confirm this point, hence the need for near term pressurized SMT tests. Conceptually, taking credit for limitations on primary loading and strain limits is analogous to the NB hopper diagram philosophy where, for example, the use of strain controlled fatigue data is predicated on the stress field surrounding a local stress riser shaking down to elastic action in accordance with the primary plus secondary stress range limits. Similarly, elastic shake down of primary plus secondary stresses is predicated on the primary stress being less than yield.

In addition to the pressurized SMT data, the modified two bar test shown in Fig. 2, Long Term Tests, will provide valuable data for verification of the effects of superimposed primary loading. The advantage of this two bar modified configuration is that all the relevant test parameters can be measured directly. If it turns out that the effect of primary loading is significant, then the proposed solution, as shown under the long term test and analytic development column, is to develop mean stress type design curves analogous to the mean stress correction curves for the fatigue evaluation of some materials below the creep regime.

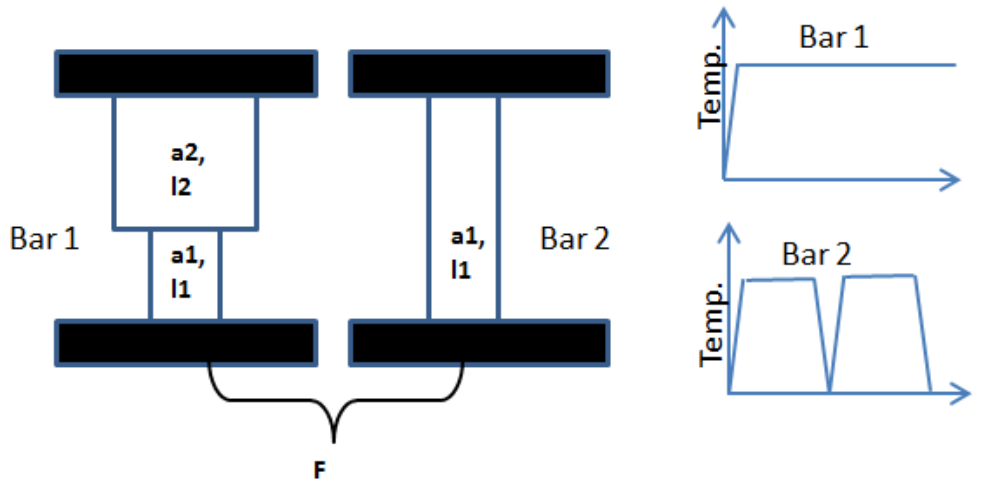

Fig. 2. Modified two-bar test.

\subsubsection{The EPP strain range determination captures the creep-fatigue degradation due to follow- up.}

In this assumption, the strain range from the strain limit code case will be modified to include creep strain, $\varepsilon_{c}$, divided by the number of cycles $N$, to estimate the additional strain per cycle due to creep. This is similar to current Div. 5 approach in HBB-T-1432(h).

As currently envisioned, the plastic strain from the EPP strain limit code case will capture the enhanced strain redistribution at both gross and local structural discontinuities. Further, the use of a pseudo stress in the elastic-perfectly plastic analysis will account for creep as well as plastic redistribution and the use of the elastic-perfectly plastic material model will also contribute to the bounding nature of the solution. However, what is not addressed directly due to the use of standard creep-fatigue test data to develop the SMT design curves is the retardation of stress relaxation due to follow-up effects. For local structural discontinuities, the surrounding stress field will tend to limit localized stress and strain redistribution and to approach the pure relaxation mode characteristic of stain controlled creep-fatigue tests. If, based on test data and analysis, additional modifications are required, then a combination of restrictions on follow-up and stress concentration factor limits per the Jetter paper (Jetter, 1998) and a creep damage enhancement factor based on nominal follow-up characteristics may be required. If required, the use of these factors and other potential considerations as discussed above will need to be factored into the creep-fatigue 
correlation equations required to develop the design curves as shown under the long term test and analytical development column heading.

As shown under the near term test and evaluation heading, the results from both the Type 1 and 2 SMT test specimens will be evaluated to determine which of the factors discussed above will be required. Interpretation of the test results will be complemented with elastic/creep simplified analytic models analogous to those used in the two bar evaluations.

\subsubsection{Long Term Tests}

Longer term tests at least provide a partial validation of the hold time extrapolation procedures developed for application to the design curves are shown on Fig. 1. The modification of the two bar test configuration is discussed above in section 2.1.1.2.

\section{EXPERIMETNAL TEST RESULTS}

\subsection{MATERIALS AND SPECIMENS}

To support this study, the Idaho National Laboratory supplied an Alloy 617 plate, Heat 314626 from ThyssenKrupp VDM USA, Inc., with dimensions of 30"×69"×1.5". The plate allows one of the SMT solid bar specimen, tubular pressurization specimen and YSMT specimen or two of the specimens for thermal ratcheting tests to be prepared in the thickness direction. The chemical composition of the plate is listed in Table 1. The specimen longitudinal direction is oriented with the rolling direction of the plate. All the specimens were tested in the as-received condition.

Table 1. Chemical compositions of Alloy 617 plate with heat number 314626 (weight \%).

\begin{tabular}{c|c|c|c|c|c|c|l|l|l|l|l|c}
\hline $\mathbf{C}$ & $\mathbf{S}$ & $\mathbf{C r}$ & $\mathbf{N i}$ & $\mathbf{M n}$ & $\mathbf{S i}$ & $\mathbf{M o}$ & $\mathbf{T i}$ & $\mathbf{C u}$ & $\mathbf{F e}$ & $\mathbf{A l}$ & $\mathbf{C o}$ & $\mathbf{B}$ \\
\hline 0.05 & $<0.002$ & 22.2 & R54.1 & 0.1 & 0.1 & 8.6 & 0.4 & 0.04 & 1.6 & 1.1 & 11.6 & $<0.001$ \\
\hline
\end{tabular}

SS316H round bar material with nominal diameter of 1 in was purchased from Outokumpu Stainless Bar, LLC. The heat number is 101076 and the as-received SS316H bar satisfies specification ASME SA497. The chemical composition of the SS316H is listed in Table 2. All the specimens were tested in the asreceived condition.

Table 2. Chemical compositions of SS316H bar with heat number 101076 (weight \%).

\begin{tabular}{c|c|c|c|c|c|c|c|c|c|c}
\hline $\mathbf{C}$ & $\mathbf{P}$ & $\mathbf{S i}$ & $\mathbf{N i}$ & $\mathbf{M n}$ & $\mathbf{N}$ & $\mathbf{T i}$ & $\mathbf{S n}$ & $\mathbf{V}$ & $\mathbf{F e}$ & $\mathbf{C b}-\mathbf{T a}$ \\
\hline 0.045 & 0.028 & 0.650 & 10.120 & 1.420 & 0.053 & 0.002 & 0.006 & 0.060 & balance & 0.014 \\
\hline $\mathbf{S}$ & $\mathbf{C r}$ & $\mathbf{C o}$ & $\mathbf{M o}$ & $\mathbf{N b}$ & $\mathbf{A l}$ & $\mathbf{B}$ & & & & \\
\hline 0.024 & 16.230 & 0.279 & 2.090 & 0.014 & 0.004 & 0.004 & & & & \\
\hline
\end{tabular}

SS304H round bar material with nominal diameter of 1 in was purchased from Outokumpu Stainless Bar, LLC. The heat number is E131181 and the as-received SS304H bar satisfies specification ASME SA497/A479M 13b. The chemical composition of the SS304H is listed in Table 3. All the specimens were tested in the as-received condition.

Table 3. Chemical compositions of SS304H bar with heat number E131181 (weight \%).

\begin{tabular}{c|c|c|c|c|c|c|c|c|c|c}
\hline $\mathbf{C}$ & $\mathbf{P}$ & $\mathbf{S i}$ & $\mathbf{N i}$ & $\mathbf{M n}$ & $\mathbf{N}$ & $\mathbf{T i}$ & $\mathbf{S n}$ & $\mathbf{V}$ & $\mathbf{F e}$ & $\mathbf{C b}-\mathbf{T a}$ \\
\hline 0.048 & 0.033 & 0.300 & 8.300 & 1.870 & 0.080 & 0.002 & 0.006 & 0.060 & balance & 0.020 \\
\hline $\mathbf{T a}$ & $\mathbf{S}$ & $\mathbf{C r}$ & $\mathbf{C o}$ & $\mathbf{M o}$ & $\mathbf{N b}$ & $\mathbf{A l}$ & $\mathbf{W}$ & $\mathbf{C u}$ & & \\
\hline 0.10 & 0.025 & 18.270 & 0.173 & 0.250 & 0.010 & 0.005 & 0.020 & 0.260 & & \\
\hline
\end{tabular}


The details of SMT testing instrumentation have been described in previous reports by Wang, et al. (2013a, 2014a and 2015a). The specimen geometries of Type 1 SMT, Type 2 SMT and pressurized SMT for Alloy 617, SS316H and SS304H are shown in Figs. 3-5.

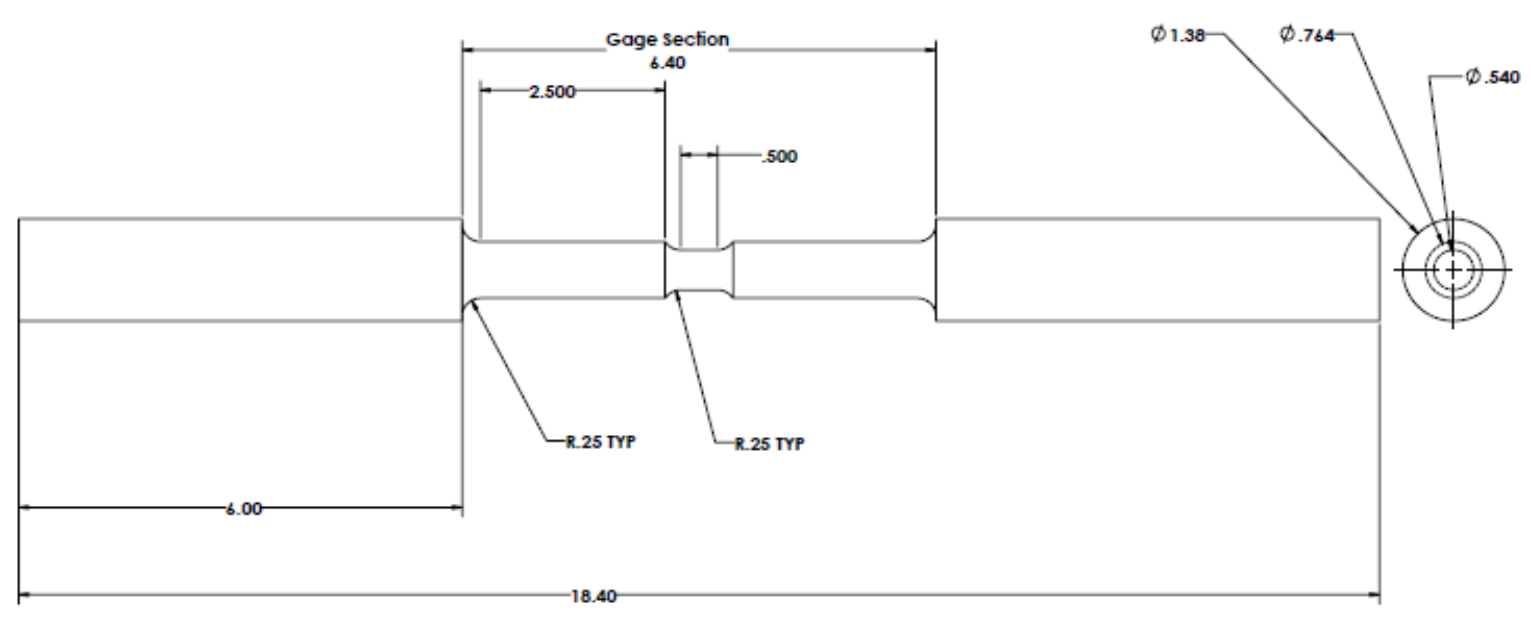

(a) Type 1 SMT geometry for Alloy 617

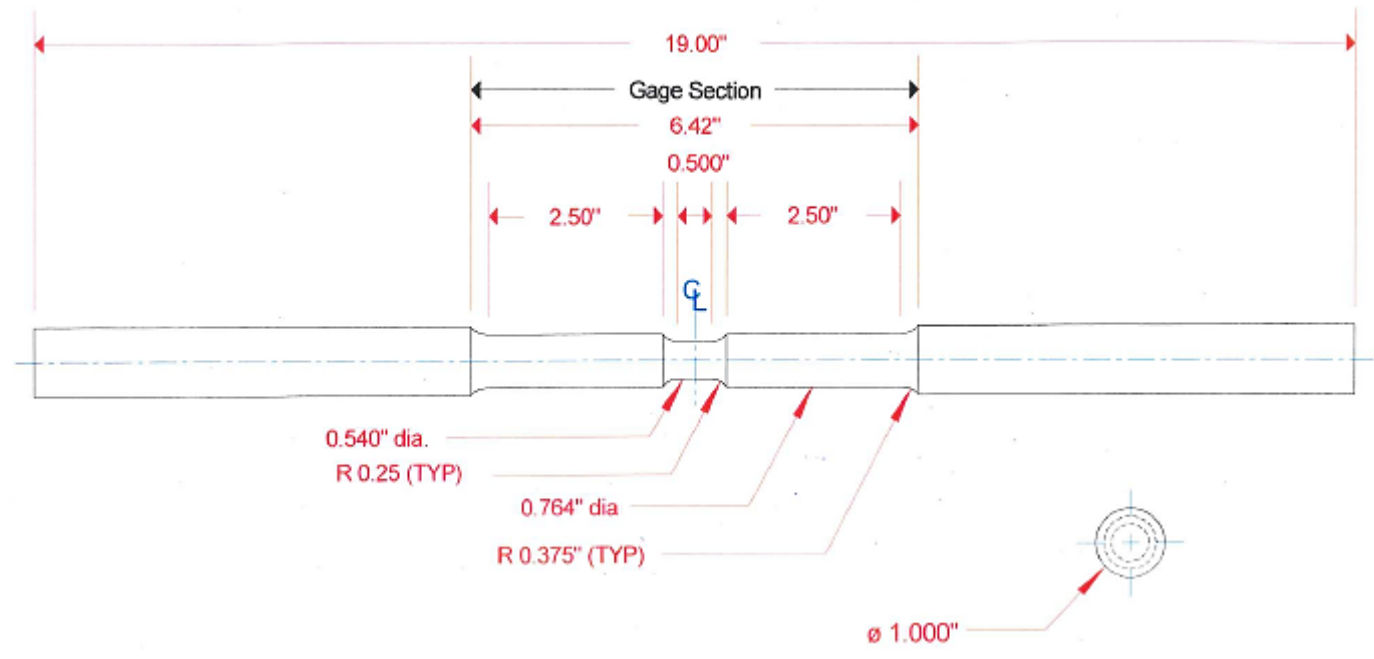

(b) Type 1 SMT geometry for SS316H and SS304H

Fig. 3. Type 1 SMT solid bar specimen geometry. Units are in inches.

In order to achieve the designed elastic follow ups for each specimen geometry, the displacement amplitude was applied to a controlled gage length section which consists of a thicker and longer driver section, a 0.5 in long necked test section and the transition regions from the driver to the necked test section. The controlled gage length is $5 \mathrm{in}$. for the Type 1 SMT and the pressurization SMT tests, and 2.9 in. for Type 2 SMT. The SMT pressurization specimen for Alloy 617 is made of three sections, i.e., a center section with two extension tabs welded together (shown in Fig. 5).

For each type of SMT specimen, the geometry within the controlled gage length section is the same for the different materials, and the differences for the specimen tab section designs are to best utilize the 
material available. An extensometer with gage length of 0.4 in. was placed to the necked test section to measure the average axial strains during SMT testing. The measured axial strains were used to generate the hysteresis loops along with the applied stresses.

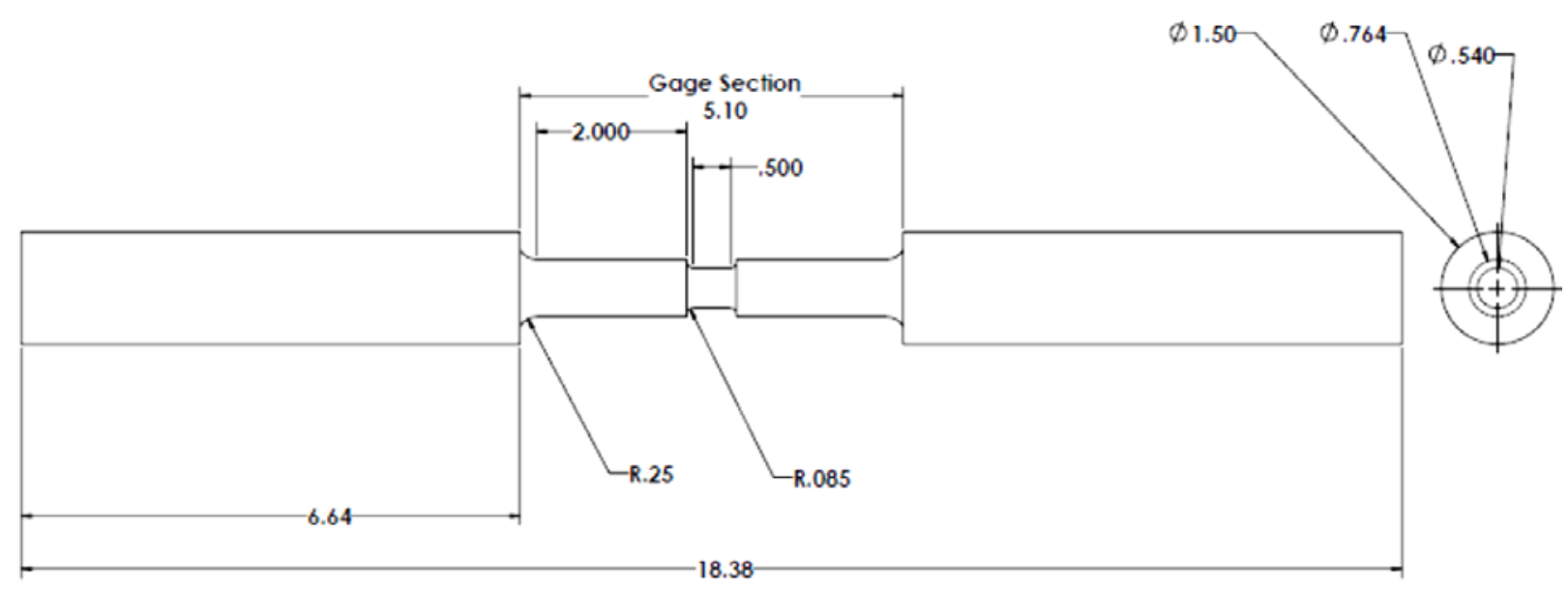

(a) Type 2 SMT geometry for Alloy 617
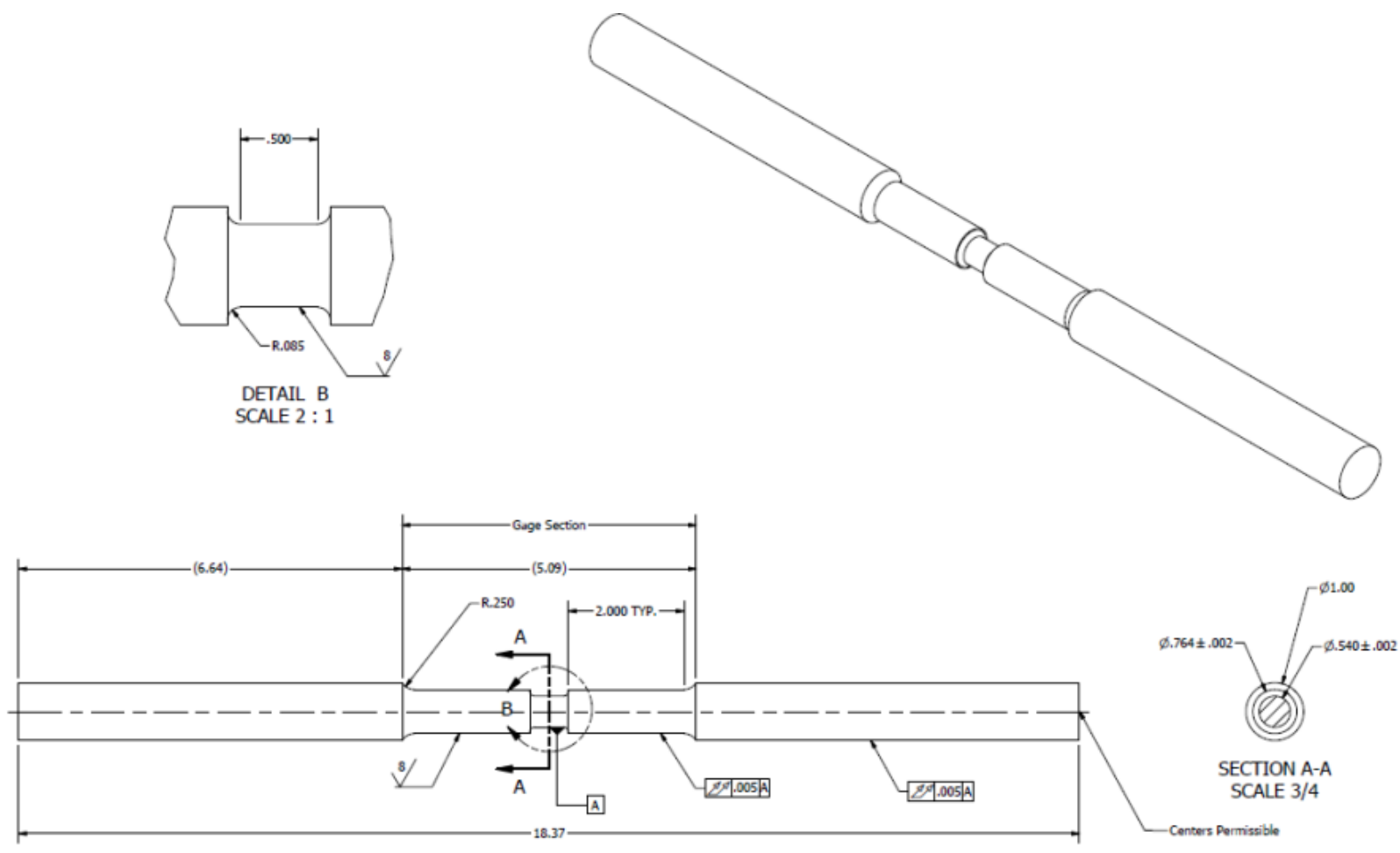

(b) Type 2 SMT geometry for SS316H and SS304H

Fig. 4. Type 2 SMT solid bar specimen geometry. Units are in inches. 

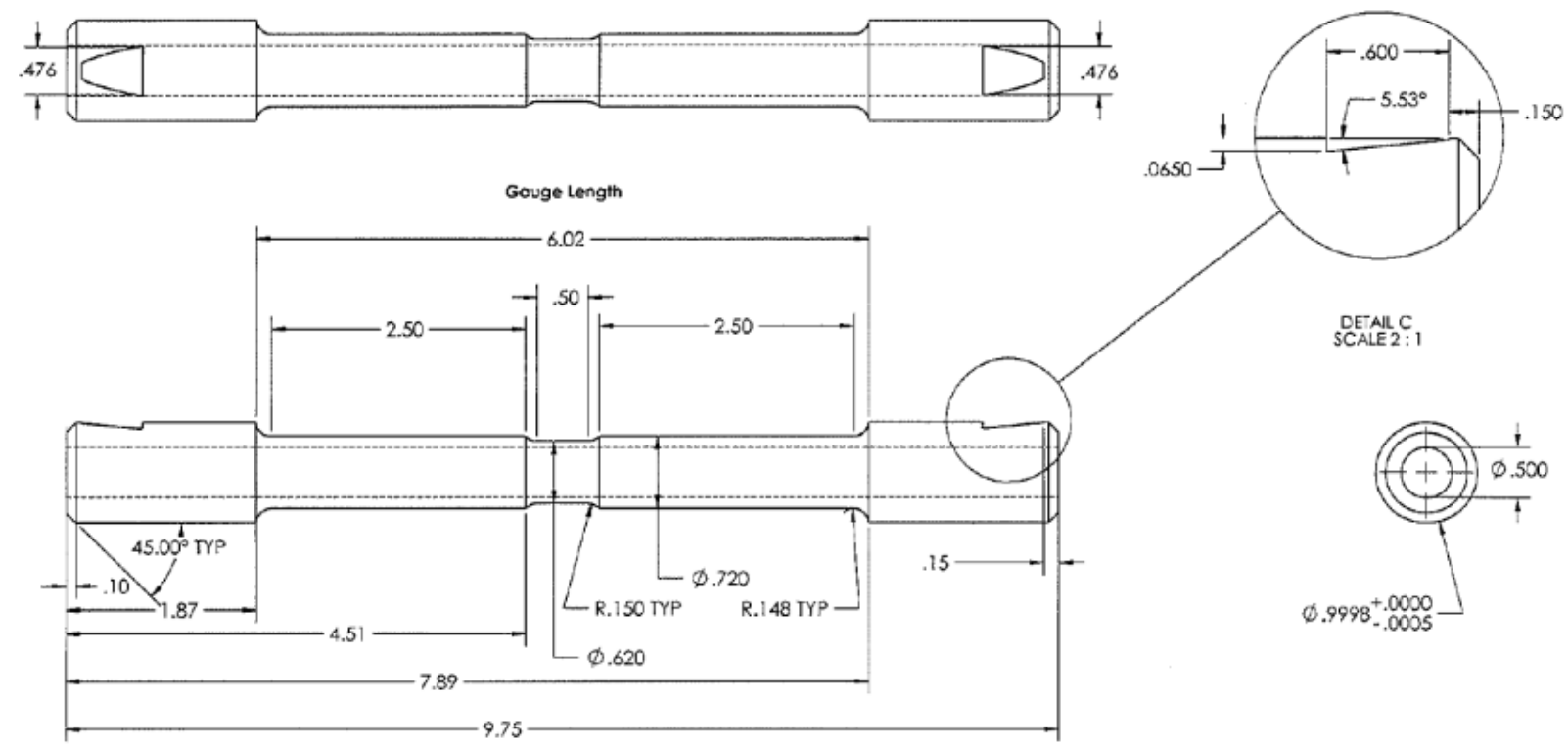

(a) Center section of the tubular SMT pressruziation specimen

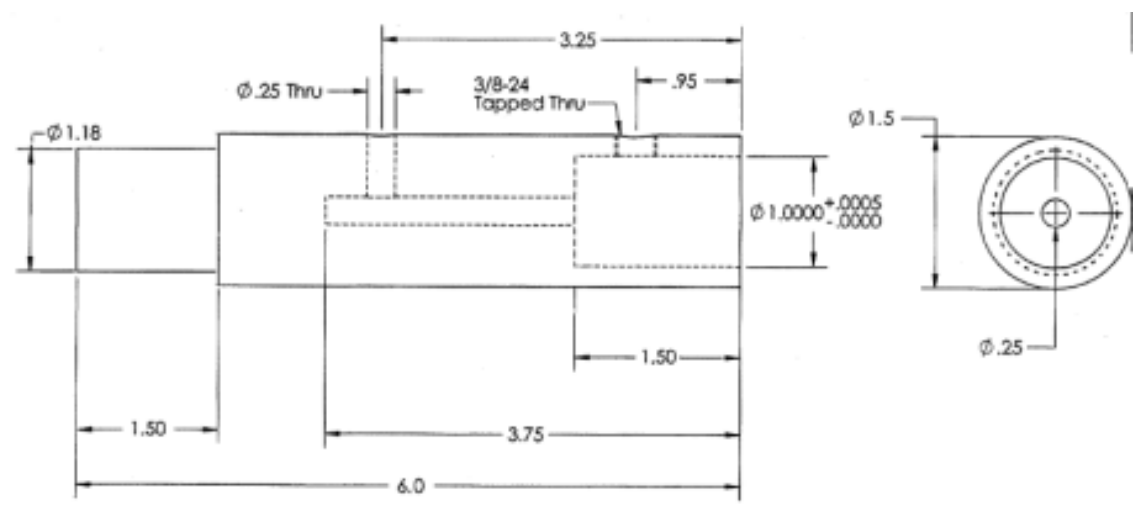

(b) Tab extension for both ends of the tubular SMT pressurzation specimen

Fig. 5. SMT pressurization specimen geometry with adaptor for Alloy 617. Units are in inches.

Figure 6 shows the YSMT specimen gometery used for testings on Aloy 617 and SS316. This YSMT was selected based on the FEM buckling anslysis and experimentally verfied using SS316 in Wang et al., 2015a. 


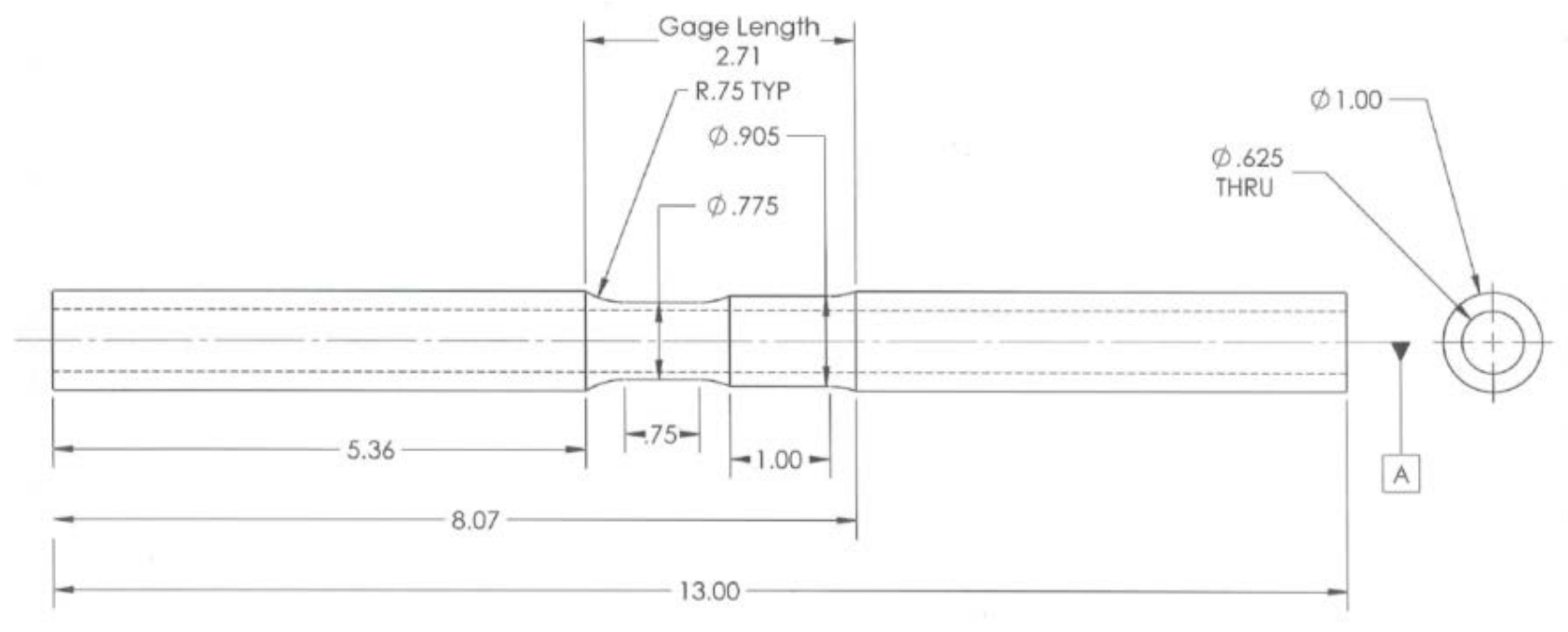

Fig. 6. YSMT specimen geometry. Units are in inches.

\subsubsection{Two-bar Thermal Ratcheting Specimen}

The heating source was a three-zone temperature controlled system with an igniter heater and resistance heating coils that are capable of providing faster heating and cooling rates such as $30^{\circ} \mathrm{C} / \mathrm{min}$. The thermal loading cycles are controlled and automated by LabView software. The temperature difference within the gage length of the specimen was less than $1 \%$ of the target temperature. Due to much more compact design of the heating system, the total length of the specimen was reduced to $7 \mathrm{in}$. The gage section of the test specimens is the same as the preceding work; with a gage length of $0.75 \mathrm{in}$. and diameter of 0.25 in. A drawing of the specimen geometry is shown in Fig. 7.

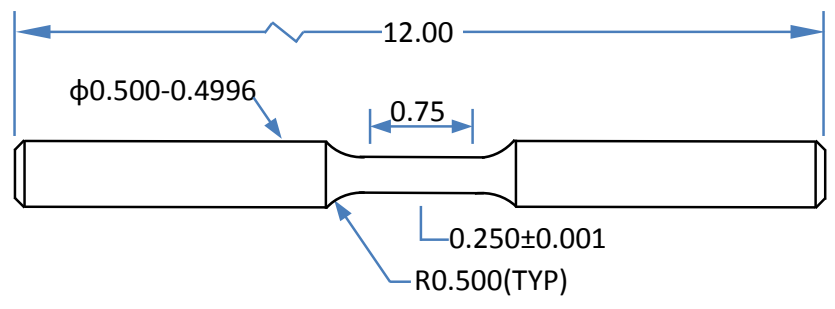

Fig. 7. Specimen geometry of Alloy 617 and SS316H used in two-bar thermal ratcheting experiments. Units are in inches.

\subsection{SMT TEST RESULTS}

\subsubsection{Summary of the Previous SMT Test Results}

The creep-fatigue tests of Alloy 617, SS304H and SS316H were performed on servo-hydraulic test machines. Tests used a fully reversed loading profile with holding time at peak tension. A schematic of the loading profile for all the previous SMT testing is show in Fig. 8; loading was automated through a LabView program. 


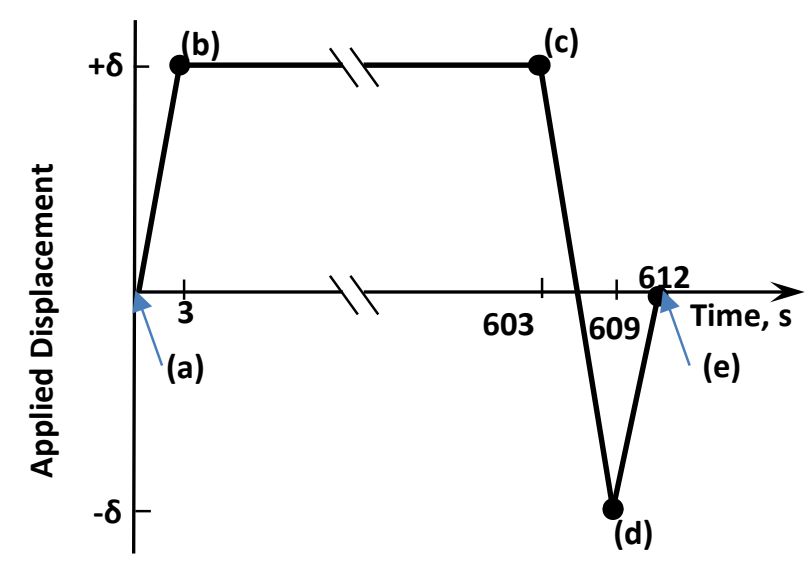

Fig. 8. Applied end-displacement profile for one cycle of creep-fatigue testing with tension hold.

The results from 15 tests are reported for Alloy 617 (Table 4), 3 tests for SS316H (Table 5) and 3 tests for SS304H (Table 6) in Wang et al. (2015a). All the previous reported tests but test \#10 used an enddisplacement profile shown in Fig.8 with 612 s per cycle. Test \#10 had a loading time and unloading time of $300 \mathrm{~s}$ and a total of 1800s for one cycle.

Table 4. Previous SMT creep-fatigue for Alloy 617.

\begin{tabular}{|c|c|c|c|c|c|c|c|c|c|}
\hline $\begin{array}{c}\text { Specimen } \\
\text { Type }\end{array}$ & $\begin{array}{l}\text { Test } \\
\text { No. }\end{array}$ & $\begin{array}{l}\text { Specimen } \\
\text { ID }\end{array}$ & $\begin{array}{c}\text { Amplitude, } \\
\delta \text { value in } \\
\text { Fig. } 8\end{array}$ & $\begin{array}{c}\text { Elastic } \\
\text { calculated } \\
\text { strain range } \\
\text { inside gage }\end{array}$ & $\begin{array}{c}\text { Hold time, } \\
(\mathbf{b}) \rightarrow(\mathbf{c}) ; \\
\text { s } \\
\text { Fig. } 8\end{array}$ & $\begin{array}{c}\text { Initial } \\
\text { strain } \\
\text { range, } \\
\%\end{array}$ & $\begin{array}{c}\text { Test } \\
\text { temperature } \\
{ }^{\circ} \mathrm{C}\end{array}$ & $\begin{array}{c}\text { Life } \\
\text { time, } \\
\text { hr }\end{array}$ & $\begin{array}{l}\text { Cycles to } \\
\text { failure }\end{array}$ \\
\hline \multirow{9}{*}{ Type 1} & $\# 1$ & R1C2 & $\begin{array}{c}4.5 \text { mil } \\
\text { Previous }\end{array}$ & $0.296 \%$ & 600 & 0.65 & 950 & 78.2 & 460 \\
\hline & $\# 2$ & R2C1 & $4.5 \mathrm{mil}$ & $0.296 \%$ & 600 & 0.63 & 950 & 76.5 & 450 \\
\hline & \#7 & R11C2 & $2.9 \mathrm{mil}$ & $0.196 \%$ & 600 & 0.25 & 950 & 170 & 1000 \\
\hline & $\# 10^{*}$ & R11C1* & $4.5 \mathrm{mil}$ & $0.296 \%$ & 600 & 0.71 & 950 & 475 & 950 \\
\hline & $\# 11$ & R16C3 & $1.8 \mathrm{mil}$ & $0.121 \%$ & 180 & 0.16 & 950 & 56 & 1050 \\
\hline & $\# 17$ & R15C2 & $2.8 \mathrm{mil}$ & $0.196 \%$ & 600 & 0.38 & 950 & 153 & 900 \\
\hline & $\# 18$ & R21C4 & $2.85 \mathrm{mil}$ & $0.196 \%$ & 600 & 0.36 & 950 & 170 & 1000 \\
\hline & \#21 & R11C3 & $4.9 \mathrm{mil}$ & $0.339 \%$ & \begin{tabular}{|c|}
$600($ cycle $>12)$ \\
$200($ cycle $1-$ \\
$12)$ \\
\end{tabular} & 0.64 & 850 & 85.4 & 510 \\
\hline & \#22 & R17C4 & $2.75 \mathrm{mil}$ & $0.183 \%$ & $\begin{array}{c}600 \text { (cycle }>17) \\
200(\text { cycle } 1- \\
17)\end{array}$ & 0.3 & 850 & 386 & 2280 \\
\hline \multirow{4}{*}{ Type 2} & $\# 4$ & R6C2 & $2.75 \mathrm{mil}$ & $0.296 \%$ & \begin{tabular}{|l|}
600 \\
\end{tabular} & 0.66 & 950 & 63 & 370 \\
\hline & $\# 5$ & R6C3 & $2.75 \mathrm{mil}$ & $0.296 \%$ & 600 & 0.62 & 950 & 60 & 350 \\
\hline & $\# 8$ & R7C2 & $1.8 \mathrm{mil}$ & $0.194 \%$ & 600 & 0.31 & 950 & 160 & 940 \\
\hline & $\# 9$ & R7C1 & $1.8 \mathrm{mil}$ & $0.194 \%$ & 600 & 0.32 & 950 & 162 & 950 \\
\hline \multirow{2}{*}{$\begin{array}{c}\text { Tubular } \\
\text { oressurization }\end{array}$} & $\# 13$ & INC617-T1 & $4.5 \mathrm{mil}$ & $0.299 \%$ & 600 & 0.7 & 950 & 20 & 120 \\
\hline & $\# 16$ & INC617-T3 & $4.5 \mathrm{mil}$ & $0.299 \%$ & 600 & 0.72 & 950 & 37 & 220 \\
\hline
\end{tabular}

Note: Test \#10 had a loading time of $300 \mathrm{~s}$. 
Table 5. Previous SMT creep-fatigue for Type 1 SS316H.

\begin{tabular}{|c|c|c|c|c|c|c|c|c|}
\hline $\begin{array}{l}\text { Test } \\
\text { No. }\end{array}$ & $\begin{array}{l}\text { Specimen } \\
\text { ID }\end{array}$ & $\begin{array}{c}\text { Amplitude, } \\
\delta \text { value in } \\
\text { Fig. } 8\end{array}$ & $\begin{array}{c}\text { Elastic } \\
\text { calculated } \\
\text { strain } \\
\text { range } \\
\text { inside } \\
\text { gage }\end{array}$ & $\begin{array}{l}\text { Hold time, } \\
\text { (b) } \rightarrow \text { (c); s } \\
\quad \text { Fig. } 8\end{array}$ & $\begin{array}{l}\text { Initial } \\
\text { strain } \\
\text { range }\end{array}$ & $\begin{array}{c}\text { Test } \\
\text { temperature } \\
{ }^{0} \mathrm{C}\end{array}$ & $\begin{array}{c}\text { Life } \\
\text { time, } \\
\text { hr }\end{array}$ & $\begin{array}{l}\text { Cycles to } \\
\text { failure }\end{array}$ \\
\hline$\# 15$ & $\begin{array}{l}\text { SS316H- } \\
\text { spec2 }\end{array}$ & $4.5 \mathrm{mil}$ & $0.296 \%$ & 600 & $0.62 \%$ & 815 & 70 & 410 \\
\hline$\# 19$ & $\begin{array}{l}\text { SS316H- } \\
\text { spec3 }\end{array}$ & $1.8 \mathrm{mil}$ & $0.125 \%$ & $\begin{array}{l}\text { 600(cycle } 1-4470) \\
180(\text { cycle }>4471)\end{array}$ & $0.17 \%$ & 815 & $>1226$ & $\begin{array}{l}>13,214 \\
\text { Not } \\
\text { failed }\end{array}$ \\
\hline$\# 20$ & $\begin{array}{l}\text { SS316H- } \\
\text { spec4 }\end{array}$ & $5.7 \mathrm{mil}$ & $0.375 \%$ & $\begin{array}{l}600(\text { cycle }>12) \\
60(\text { cycle } 1-12)\end{array}$ & $0.62 \%$ & 650 & 172 & 1020 \\
\hline
\end{tabular}

Table 6. Previous SMT creep-fatigue for Type 1 SS304H.

\begin{tabular}{c|c|c|c|c|c|c|c|c}
\hline Test No. & $\begin{array}{c}\text { Specimen } \\
\text { ID }\end{array}$ & $\begin{array}{c}\text { Amplitude, } \\
\mathbf{\delta} \text { value in } \\
\text { Fig. 8 }\end{array}$ & $\begin{array}{c}\text { Elastic } \\
\text { calculated } \\
\text { strain } \\
\text { range } \\
\text { inside } \\
\text { gage }\end{array}$ & $\begin{array}{c}\text { Hold } \\
\text { time, } \\
(\mathbf{b}) \rightarrow(\mathbf{c}) \text {; } \\
\mathbf{s} \\
\text { Fig. } 8\end{array}$ & $\begin{array}{c}\text { Initial } \\
\text { strain } \\
\text { range }\end{array}$ & $\begin{array}{c}\text { Test } \\
\text { temperature } \\
\mathbf{0} \mathbf{C}\end{array}$ & $\begin{array}{c}\text { Life } \\
\text { time, } \\
\mathbf{h r}\end{array}$ & $\begin{array}{c}\text { Cycles } \\
\text { to } \\
\text { failure }\end{array}$ \\
\hline$\# 24$ & $\begin{array}{c}\text { SS304H- } \\
\text { spec8 }\end{array}$ & 3.9 mil & $0.257 \%$ & 600 & $0.60 \%$ & 815 & 66 & 390 \\
\hline$\# 25$ & $\begin{array}{c}\text { SS304H- } \\
\text { spec2 }\end{array}$ & $4.5 \mathrm{mil}$ & $0.296 \%$ & 600 & $0.78 \%$ & 815 & 29 & 170 \\
\hline 26 & $\begin{array}{c}\text { SS304H- } \\
\text { spec7 }\end{array}$ & $4.5 \mathrm{mil}$ & $0.296 \%$ & 600 & $0.50 \%$ & 650 & 264 & 1550 \\
\hline
\end{tabular}

\subsubsection{Type 1 SMT Testing on Alloy 617}

The broader goal of the SMT approach is to develop a methodology for evaluation of creep fatigue damage which is simpler to implement than the current complex rules and applicable to the full temperature range from ambient conditions to the very high temperature creep regime of $900^{\circ} \mathrm{C}$ to $950^{\circ} \mathrm{C}$. Experimental SMT results from lower temperature testing are also of great interest for verification of the design rules. To support this, SMT test \# 27 was performed at much lower temperature of $650{ }^{\circ} \mathrm{C}$ with an elastically calculated strain range of $0.4 \%$ at the necked test section on a Type 1 SMT specimen with tension-hold only loading profile. The test had $\sim 5200$ cycles to failure. The total ratcheting strain for the test section was found to be less than $1 \%$. It is noted that this test had minor control issues throughout the long test period, but the test data is of value for reference for this low temperature test condition. The results are summarized in Table 7 and plots of the measured strain range and maximum (tension) and minimum (compressive) stress as a function of cycle number, representative hysteresis loops and stress history are presented in Fig. 9. 


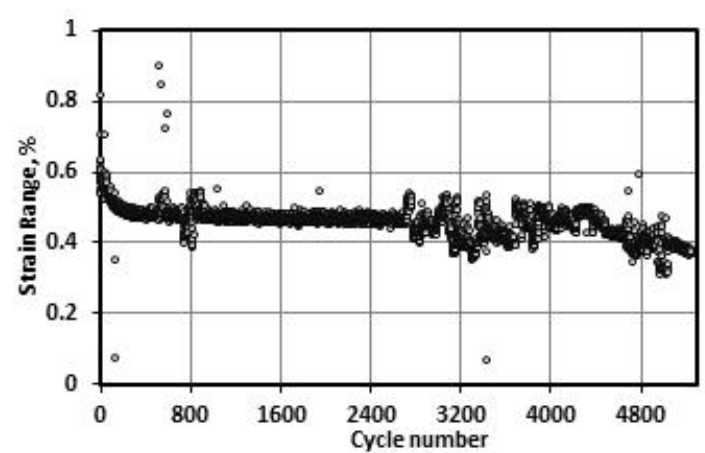

(a) Strain range

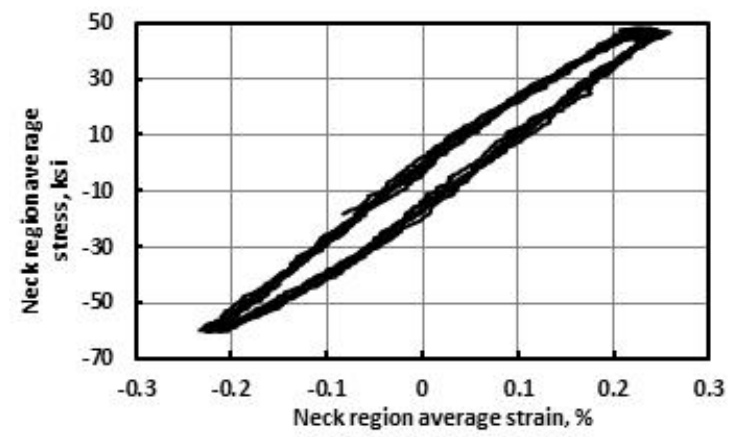

(c) Hysteresis Loop

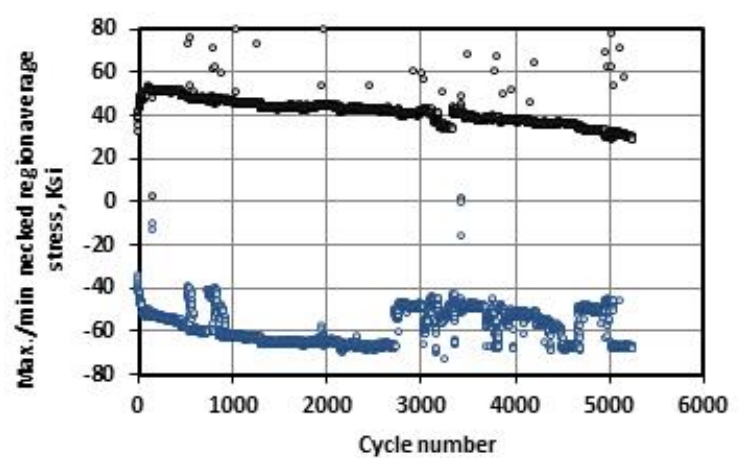

(b) Max/Min stresses

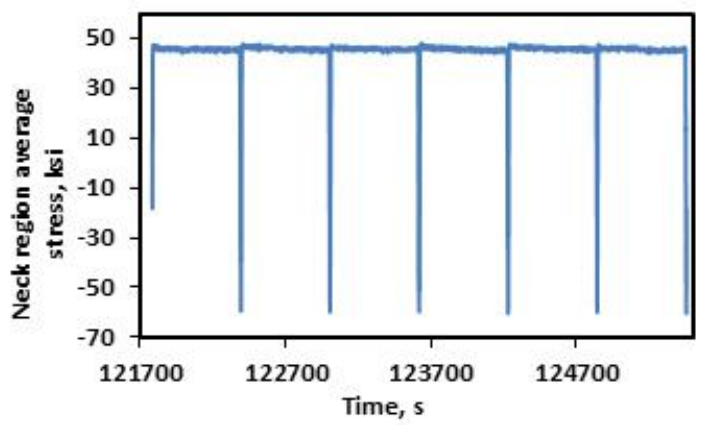

(d) Stress relaxation

Fig. 9. Test results for test \#27.

Additionally, SMT Creep-Fatigue tests were performed on Type 1 Alloy 617 solid bar specimens with compression hold or combined tensile-compression hold test conditions. The purpose of SMT testing with these different loading profiles was to evaluate the material behavior under SMT testing condition and to identify the most damaging deformation mode. The applied end-displacement profiles for one cycle with compression hold or combined tensile-compression hold are schematically shown in Fig. 10. The compression-hold only test had a hold time of $600 \mathrm{~s}$ with a $612 \mathrm{~s}$ per cycle. The combined compressiontension hold had a hold time of $600 \mathrm{~s}$ on the tension peak and a $600 \mathrm{~s}$ hold on the compression peak with a total of 1212 s per cycle. Test \#31 and \#32 had an elastically calculated strain range of $0.3 \%$ at the necked test section and test \#33 and \#34 had elastically calculated strain range of $0.2 \%$ at the necked test section. All tests were performed at $950{ }^{\circ} \mathrm{C}$ and the results are summarized in Table 7. 


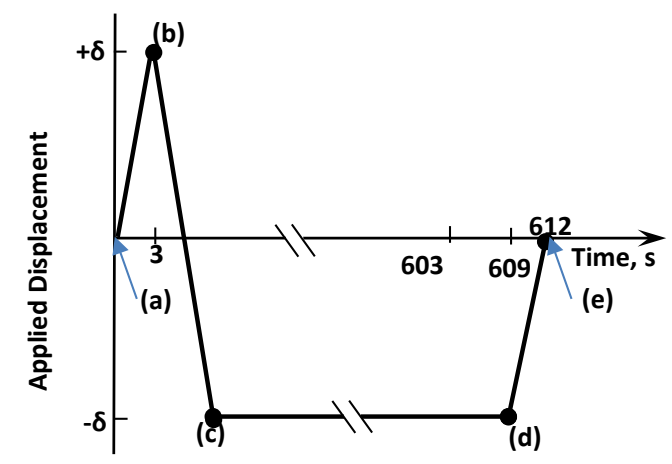

(a)

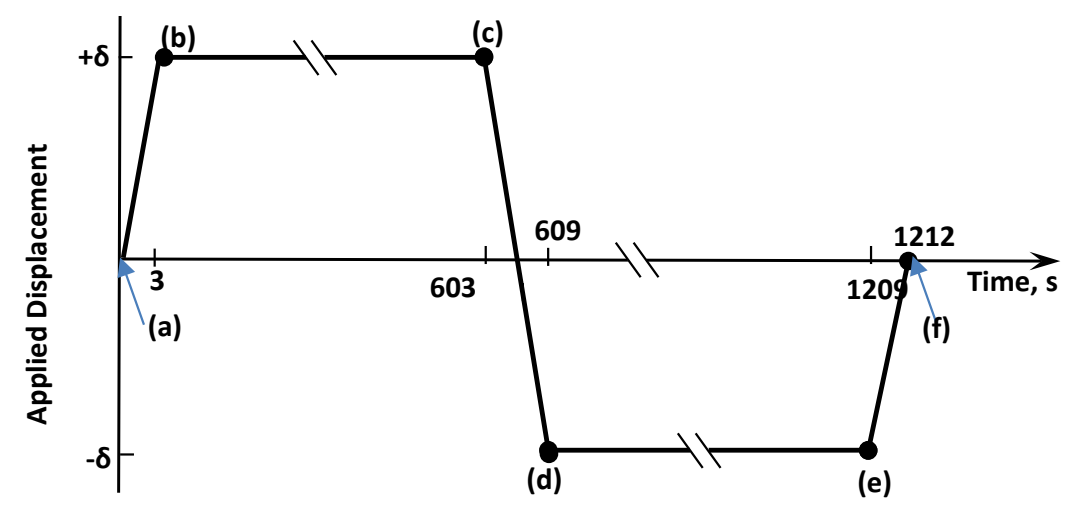

(b)

Fig. 10. Applied end-displacement profile for one cycle of creep-fatigue testing with compression hold (a) and combined tensile-compression hold (b).

Table 7. SMT creep-fatigue for Type 1 Alloy 617.

\begin{tabular}{l|c|c|c|c|c|c|c|c|c}
\hline $\begin{array}{l}\text { Test } \\
\text { No. }\end{array}$ & $\begin{array}{c}\text { Specimen } \\
\text { ID }\end{array}$ & $\begin{array}{c}\text { Amplitude, } \\
\boldsymbol{\delta} \text { value in } \\
\text { Fig. } 8\end{array}$ & $\begin{array}{c}\text { Elastic } \\
\text { calculated } \\
\text { strain } \\
\text { range } \\
\text { inside } \\
\text { gage }\end{array}$ & $\begin{array}{c}\text { Hold } \\
\text { time, } \\
\mathbf{s}\end{array}$ & $\begin{array}{c}\text { Initial } \\
\text { strain } \\
\text { range }\end{array}$ & $\begin{array}{c}\text { Test } \\
\text { temperature } \\
{ }^{\mathbf{0}} \mathbf{C}\end{array}$ & $\begin{array}{c}\text { Life } \\
\text { time, } \\
\mathbf{h r}\end{array}$ & $\begin{array}{c}\text { Applied } \\
\text { Cycles } \\
\text { to } \\
\text { failure }\end{array}$ & $\begin{array}{c}\text { displacement } \\
\text { profile }\end{array}$ \\
\hline$\# 27$ & R19C4 & $6.1 \mathrm{mil}$ & $0.401 \%$ & 600 & $0.47 \%$ & 650 & 833.6 & 5200 & Fig. 8 \\
\hline$\# 31$ & R7C3 & $4.5 \mathrm{mil}$ & $0.296 \%$ & 600 & $0.73 \%$ & 950 & 102 & 600 & Fig. 10a \\
\hline$\# 32$ & R17C3 & $4.5 \mathrm{mil}$ & $0.296 \%$ & 600 & $0.95 \%$ & 950 & 202 & 600 & Fig. 10b \\
\hline$\# 33$ & R20C3 & $2.9 \mathrm{mil}$ & $0.196 \%$ & 600 & $0.60 \%$ & 950 & 353.5 & 1050 & Fig. 10b \\
\hline$\# 34$ & R18C3 & $2.9 \mathrm{mil}$ & $0.196 \%$ & 600 & $0.41 \%$ & 950 & 204 & 1200 & Fig. 10a \\
\hline
\end{tabular}

Shown in Fig. 11 to 14 are plots of the measured strain range and maximum (tension) and minimum (compressive) stress as a function of cycle number, representative hysteresis loops, stress history, ratcheting strain and picture of the failed specimen for tests on Alloy 617. The SMT \#31 was performed with compression hold time of $600 \mathrm{~s}$, and failed at about 600 cycles. The average strain measured at the necked test section was found to be ratcheting to the tensile direction for this test. The specimen failed at the center of the necked test section with significant amount of necking. This observation is consistent with the effect of tensile ratcheting. Test \#32 with combined tension-compression also failed after 600 cycles despite the much larger strain range of $0.95 \%$. However, since the total hold time per complete cycle, $600 \mathrm{~s}$ each in tension and compression, is twice the hold time in compression-hold only, the total 
test duration of the combined tension and compression hold test was about twice the duration of the compression-hold only test. It is also noted that the combined tensile-compression hold testing slowed down the tensile ratcheting rate and the specimen failed at the transition radius.

Comparing these two tests with previous tension-hold only tests \#1 and \#2 listed in Table 4, both compression-hold only test and the combined tension-compression hold tests showed longer life time. This set of test data indicate that the tension-hold only SMT testing for Alloy 617 is more damaging at elastically calculated strain range of $0.3 \%$.

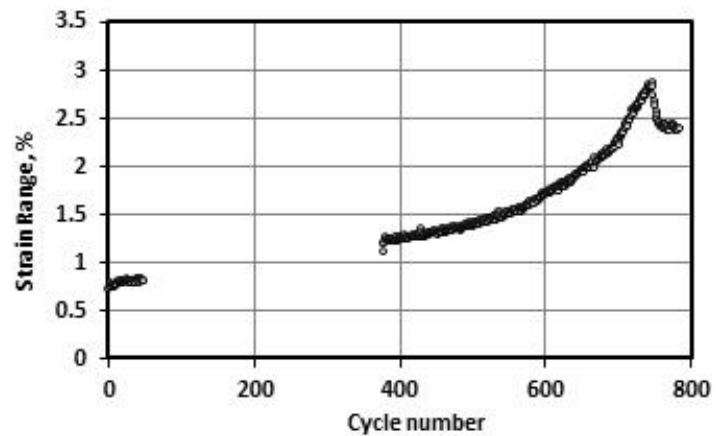

(a) Strain range

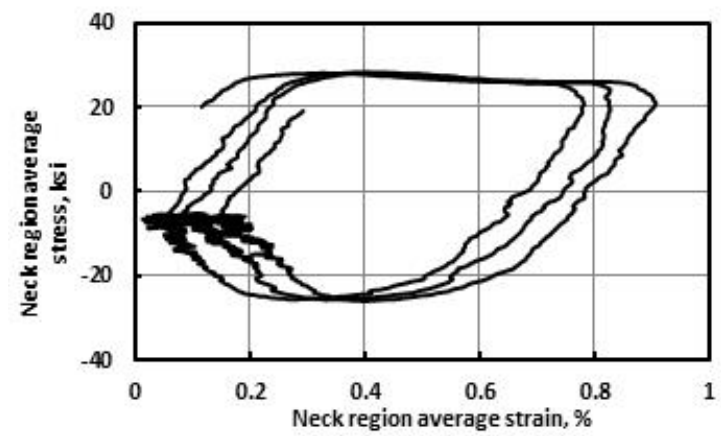

(c) Hysteresis Loop

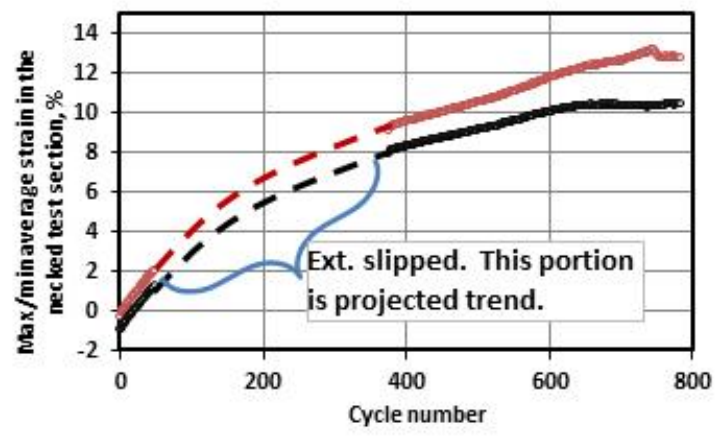

(e) ratcheting strain

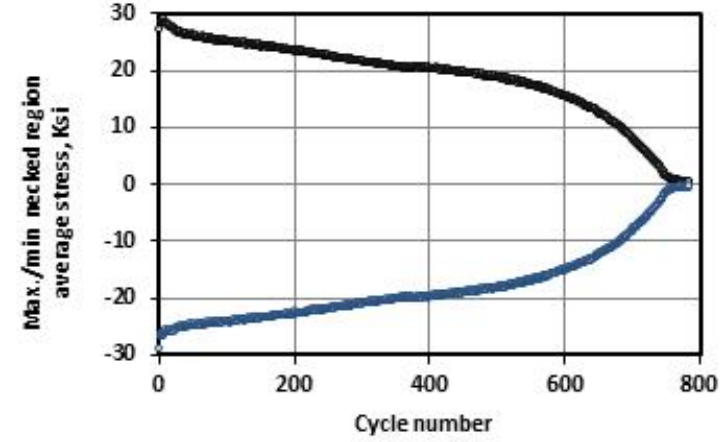

(b) Max/Min stresses

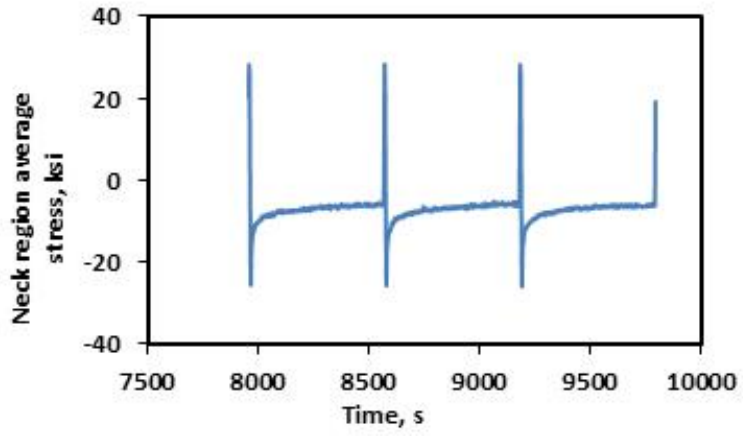

(d) Stress relaxation

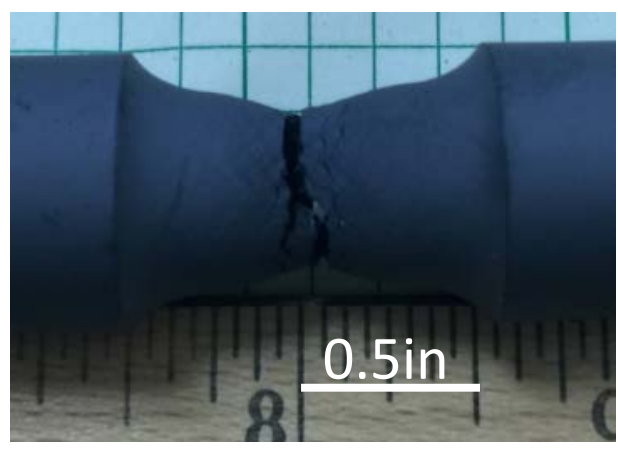

(f) failed specimen

Fig. 11. Test results for test \#31. 


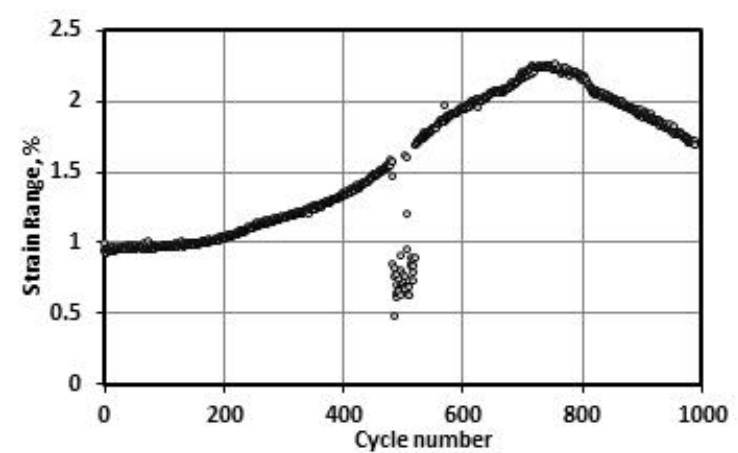

(a) Strain range

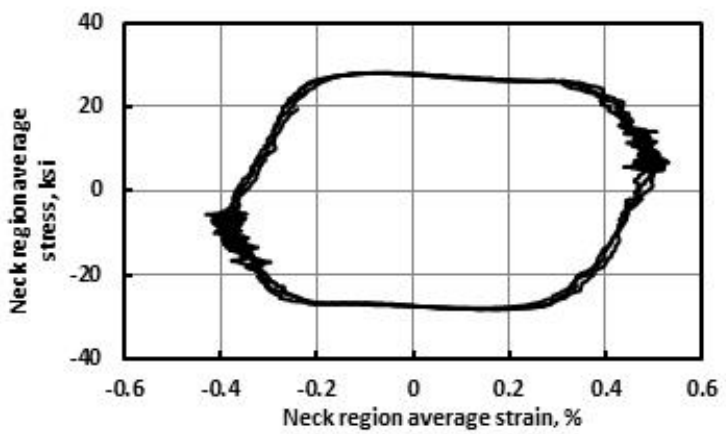

(c) Hysteresis Loop

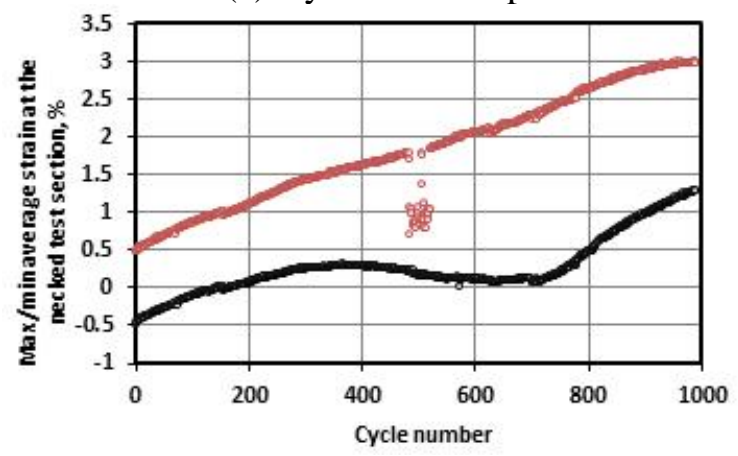

(e) ratcheting strain

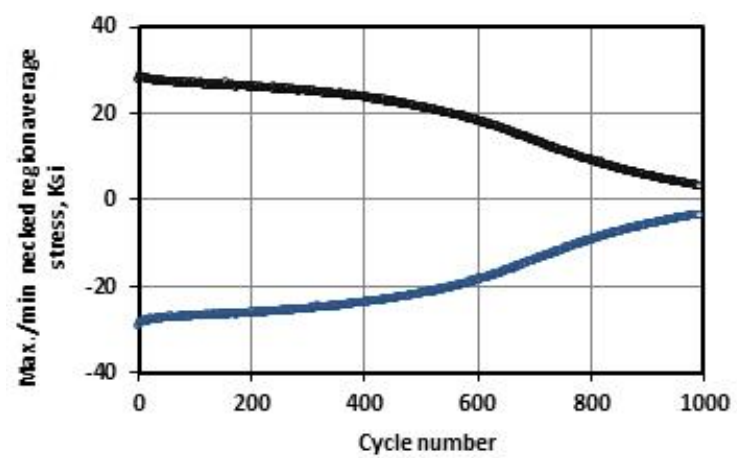

(b) Max/Min stresses

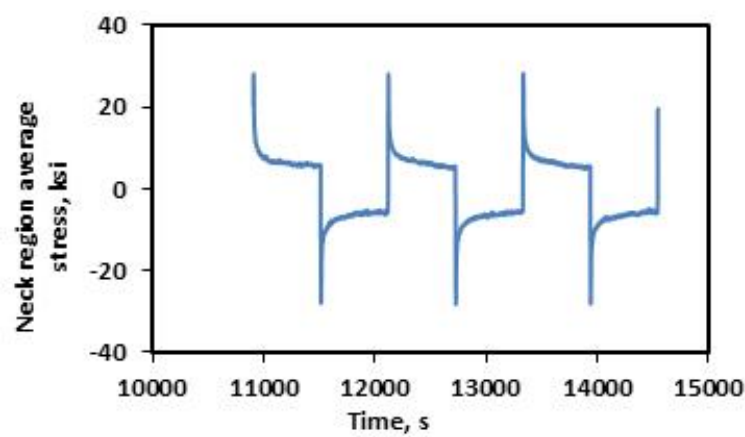

(d) Stress relaxation

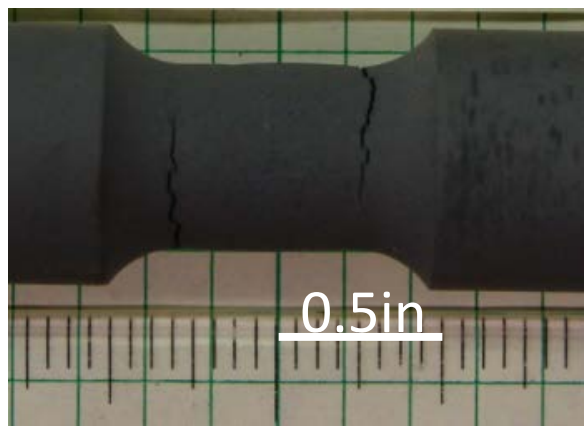

(f) failed specimen

Fig. 12. Test results for test \#32.

SMT Creep-Fatigue test \#33 and \#34 were performed on Type 1 Alloy 617 solid bar specimens at $950{ }^{\circ} \mathrm{C}$ with an elastic calculated strain range of $0.2 \%$ at the necked test section. Test \#33 (Fig. 13) was performed with combined tension-compression hold time of $600 \mathrm{~s}$ each hold, and failed at the transition radius at about 1050 cycles or 354 hrs. The SMT test \#34 (Fig. 14) was performed with compression-hold only loading profile and failed at about 1200 cycles or $204 \mathrm{hrs}$. The specimen experienced a large total amount of tensile ratcheting strain and failed at the center of the necked test section with significant amount of necking.

Compared to the tension-hold only test results from test \#7, \#17 and \#18, the test with compression-hold only condition failed after a slightly larger number of cycles and the test with combined tensioncompression hold condition failed in a similar number of complete cycles. However, since the total hold time per complete cycle, 10 minutes each in tension and compression is twice the hold time tension or compression-hold only, the total test duration of the combined tension-compression hold test was about 
twice the duration of the tension or compression-hold only test. Interestingly, the overall ratcheting was less than $1 \%$ with combined tension-compression deformation.

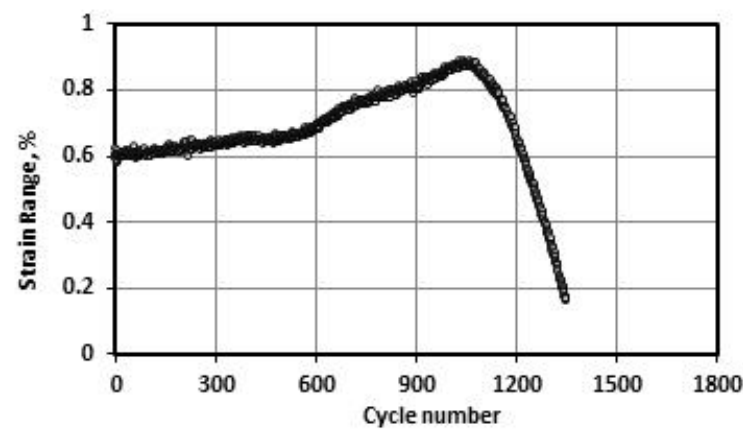

(a) Strain range

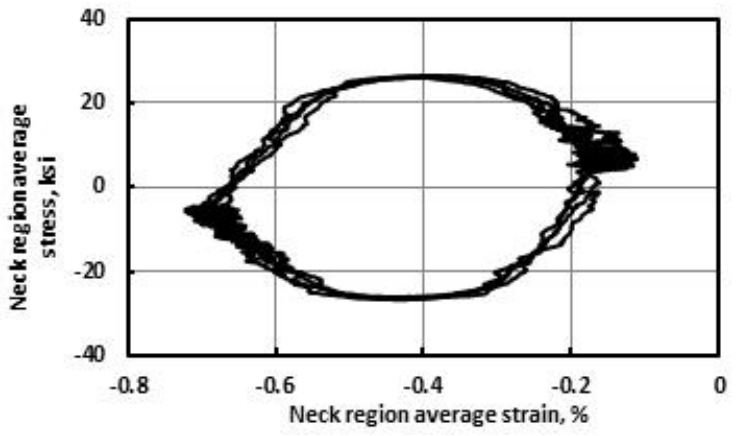

(c) Hysteresis Loop

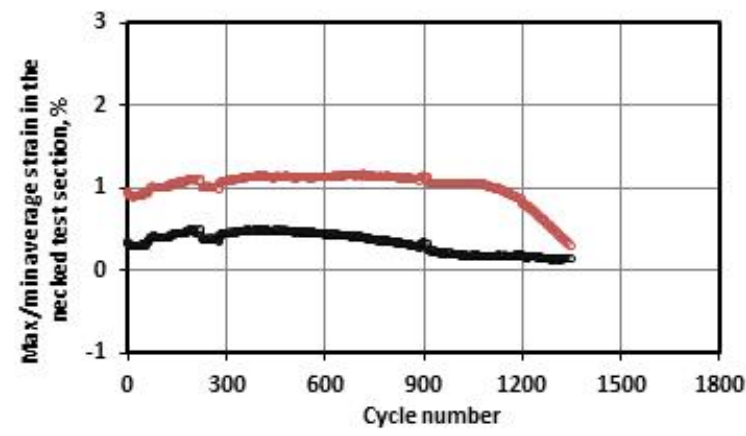

(e) ratcheting strain

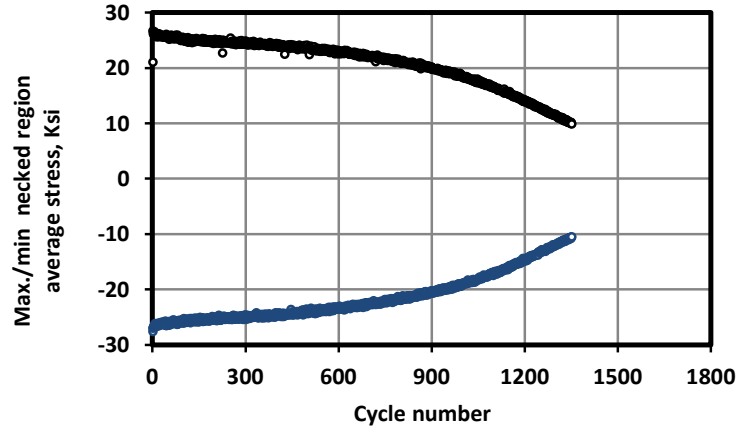

(b) Max/Min stresses

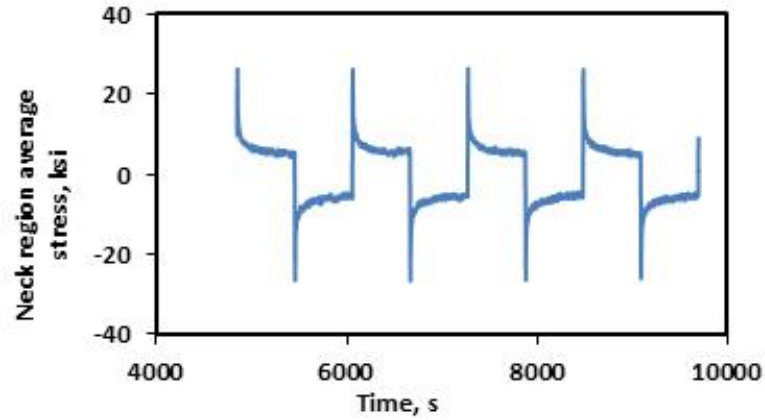

(d) Stress relaxation

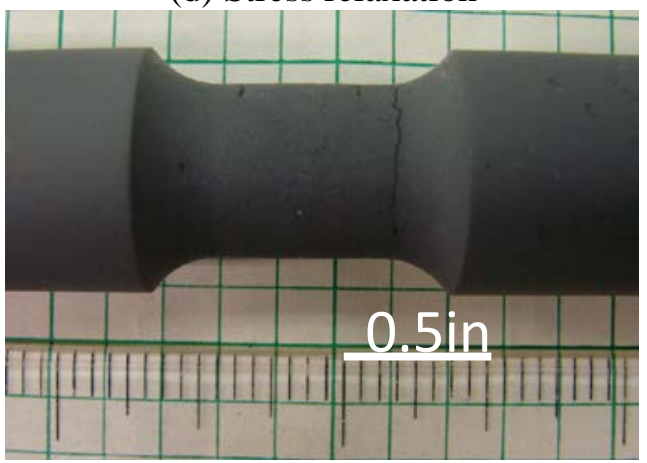

(f) failed specimen

Fig. 13. Test results for test \#33. 


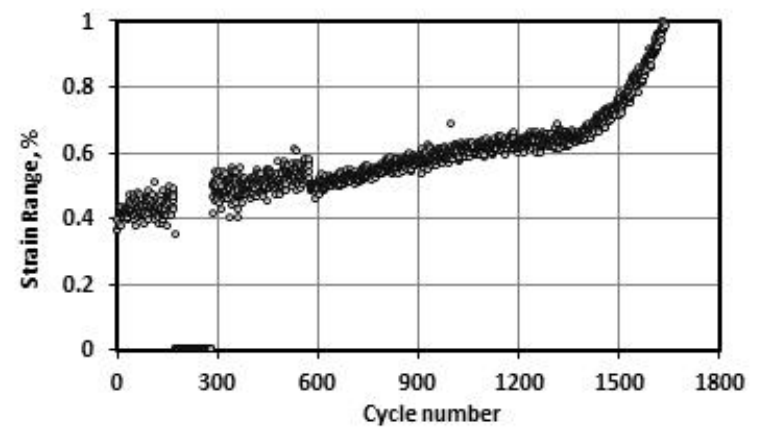

(a) Strain range

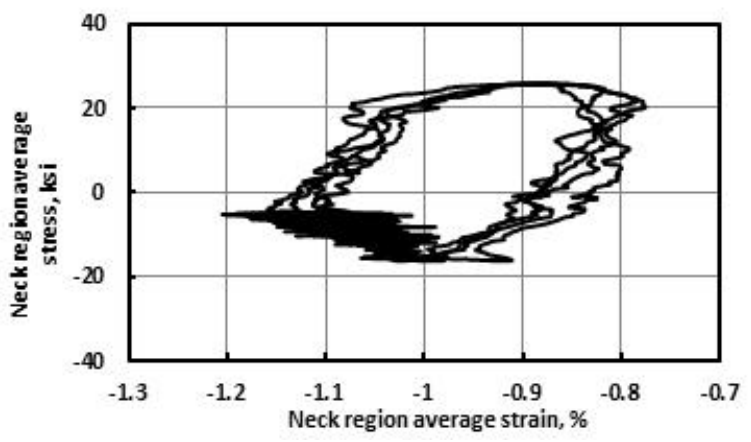

(c) Hysteresis Loop

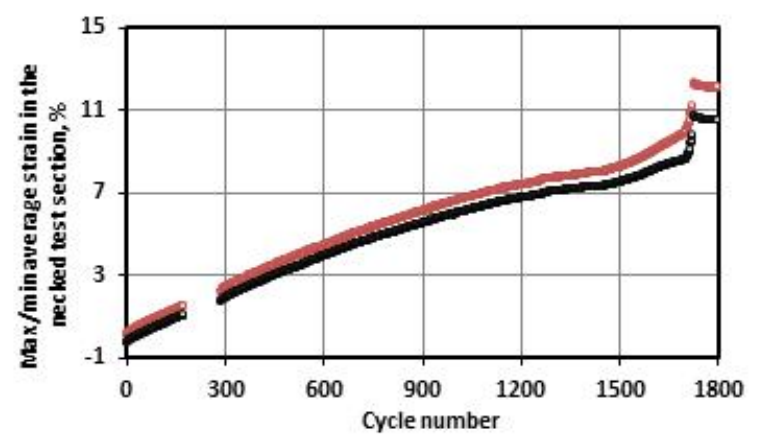

(e) ratcheting strain

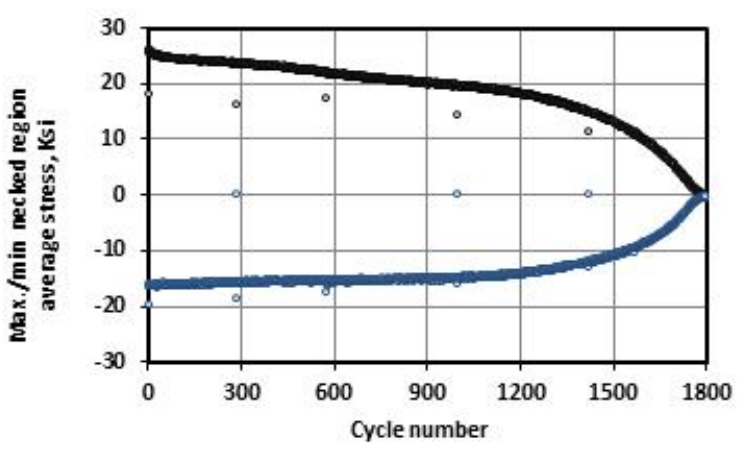

(b) Max/Min stresses

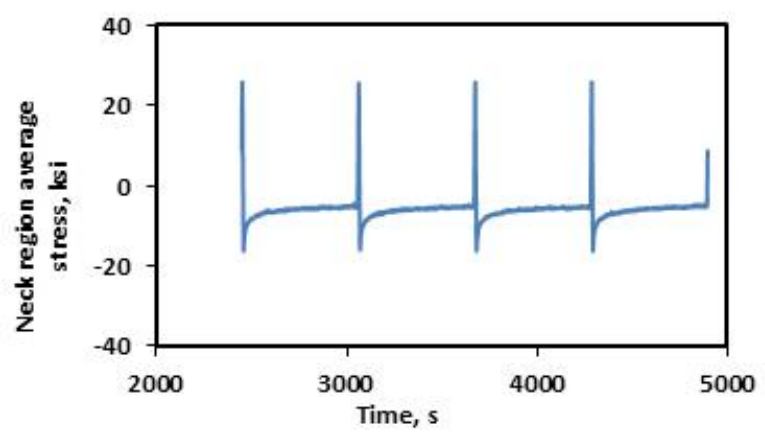

(d) Stress relaxation

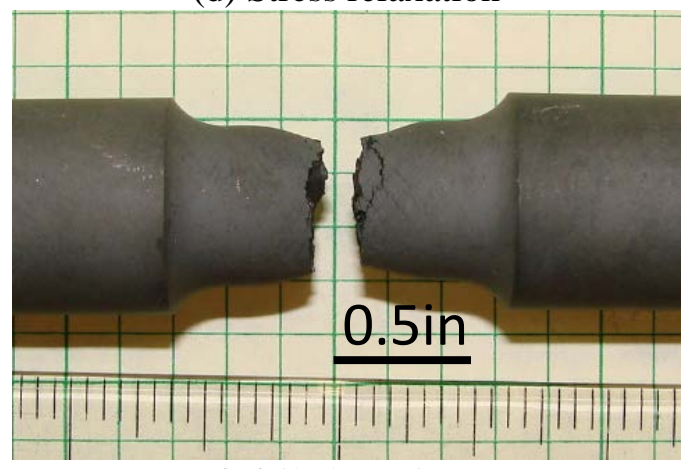

(f) failed specimen

Fig. 14. Test results for test \#34.

\subsubsection{SMT Pressurization Test on Alloy 617}

In this reporting period, a new testing machine was established for testing of SMT with pressurization. The new system was tested and tuned. Two of the tubular Alloy 617 specimens were tested at $950{ }^{\circ} \mathrm{C}$ with this new system using tension-hold only displacement loading profile. The tests were performed with an elastically calculated strain range of $0.3 \%$ using loading displacement amplitude of 4.5 mils to repeat the same test conditions performed on the original SMT machine previously, i.e., INC617-T1 and INC617-T3 in Table 4.

The test results are summarized in Table 8. Plots of the measured strain range and maximum (tension) and minimum (compressive) stress as a function of cycle number, representative hysteresis loops, stress history, ratcheting strain and failed specimen for the these two tests on Alloy 617 are presented in Fig. 15 and Fig. 16. These two tests showed similar initial strain range and 220 cycles to failure. Both specimens showed an elastic follow up factor of $\sim 3.8$. The ratcheting behaviors of the two specimens were both 
toward the compressive direction and the ratcheting rate was similar. Both specimens failed at the center of the necked test section with significant amount of barreling. Thus, it can be concluded that the $200 \mathrm{psi}$ internal pressure did not make much difference in terms of the specimen behavior for these two tests. This is an important initial finding as it supports the assumption that the SMT design curves will be independent of primary load.

Table 8. SMT pressurization for Alloy 617.

\begin{tabular}{c|c|c|c|c|c|c|c|c|c}
\hline $\begin{array}{c}\text { Specimen } \\
\text { Type }\end{array}$ & $\begin{array}{c}\text { Specimen } \\
\text { ID }\end{array}$ & $\begin{array}{c}\text { Amplitude, } \\
\mathbf{\delta} \text { value in } \\
\text { Fig. 8 }\end{array}$ & $\begin{array}{c}\text { Elastic } \\
\text { calculated } \\
\text { strain range } \\
\text { inside gage }\end{array}$ & $\begin{array}{c}\text { Hold time, } \\
\text { (b) } \rightarrow(\mathbf{c}) ; \\
\text { Fig. 8 }\end{array}$ & $\begin{array}{c}\text { Initial } \\
\text { strain } \\
\text { range }\end{array}$ & $\begin{array}{c}\text { Test } \\
\text { temperature } \\
\mathbf{0} \mathbf{C}\end{array}$ & $\begin{array}{c}\text { Life } \\
\text { time, } \\
\mathbf{h r}\end{array}$ & $\begin{array}{c}\text { Cycles } \\
\text { to } \\
\text { failure }\end{array}$ & $\begin{array}{l}\text { pnternal } \\
\text { pressure }\end{array}$ \\
\hline $\begin{array}{c}\text { Tubular } \\
\text { pressurization }\end{array}$ & $\begin{array}{c}\text { INC617- } \\
\text { P01 }\end{array}$ & 4.5 mil & $0.299 \%$ & $600 \mathrm{~s}$ & $0.8 \%$ & 950 & 37.4 & 220 & $2 \mathrm{psi}$ \\
\cline { 2 - 10 } & $\begin{array}{c}\text { INC617- } \\
\text { P02 }\end{array}$ & $4.5 \mathrm{mil}$ & $0.299 \%$ & $600 \mathrm{~s}$ & $0.8 \%$ & 959 & 37.4 & 220 & $200 \mathrm{psi}$ \\
\hline
\end{tabular}

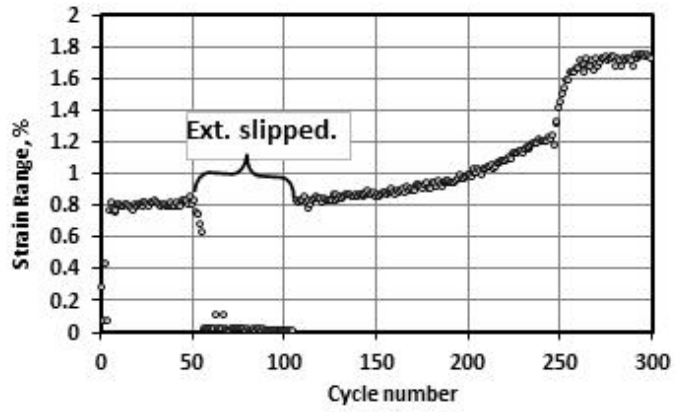

(a) Strain range

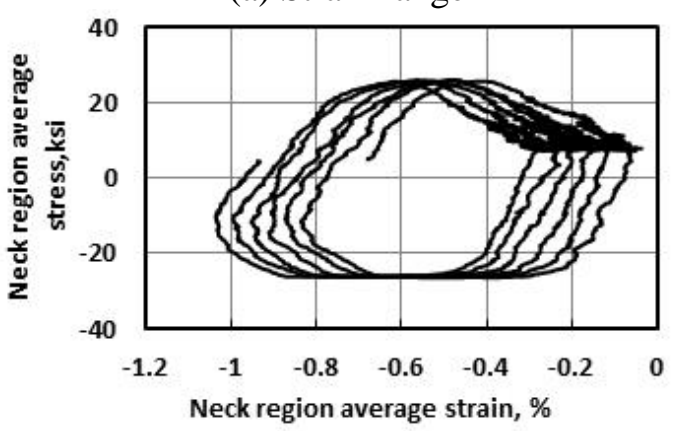

(c) Hysteresis Loop

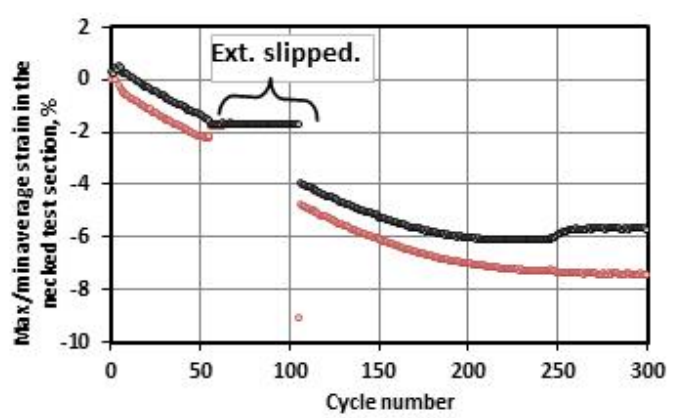

(e) ratcheting strain

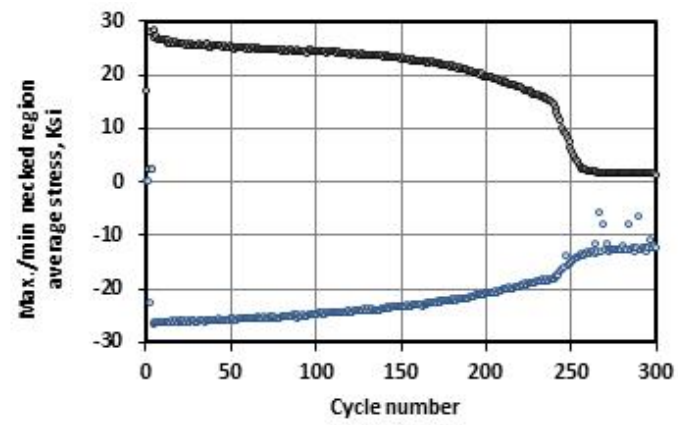

(b) Max/Min stresses

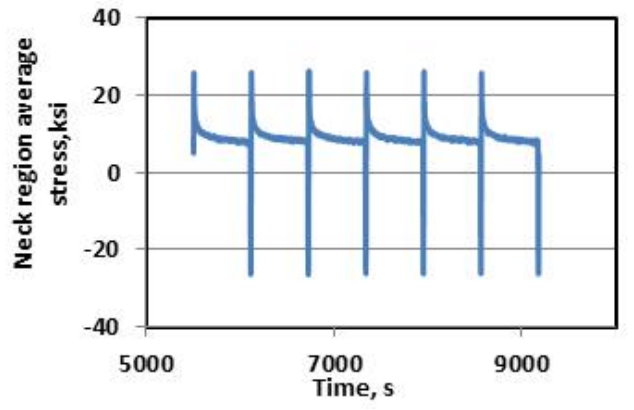

(d) Stress relaxation

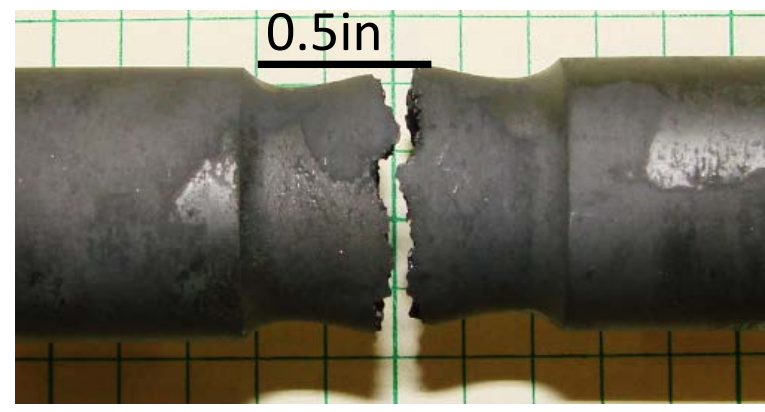

(f) failed specimen

Fig. 15. Test results for test Inc617-P01. 


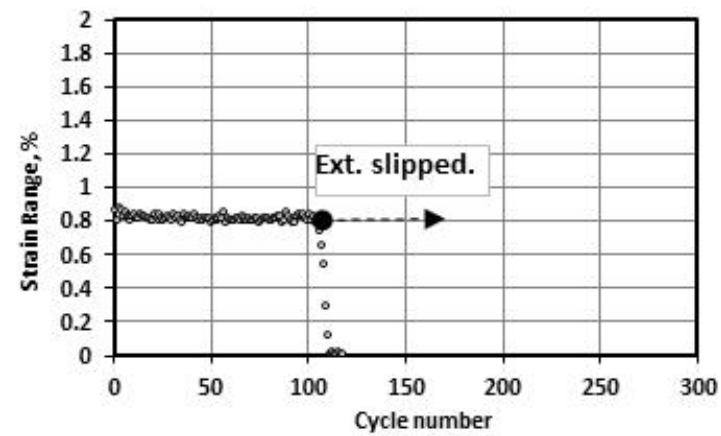

(a) Strain range

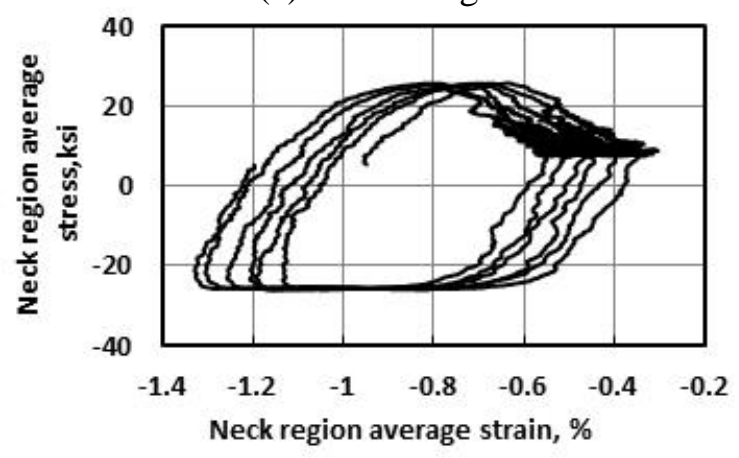

(c) Hysteresis Loop

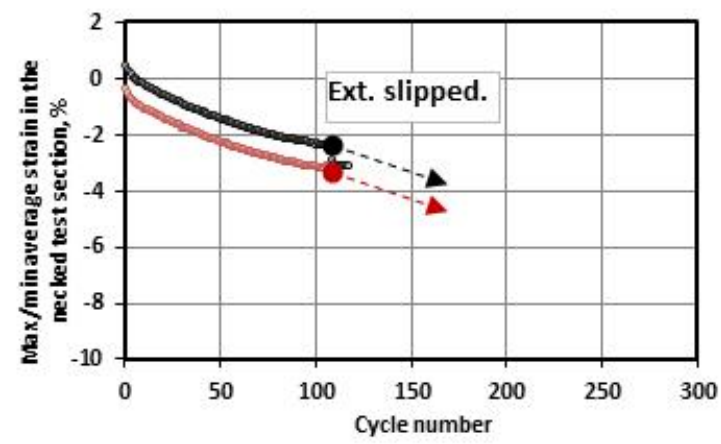

(e) ratcheting strain

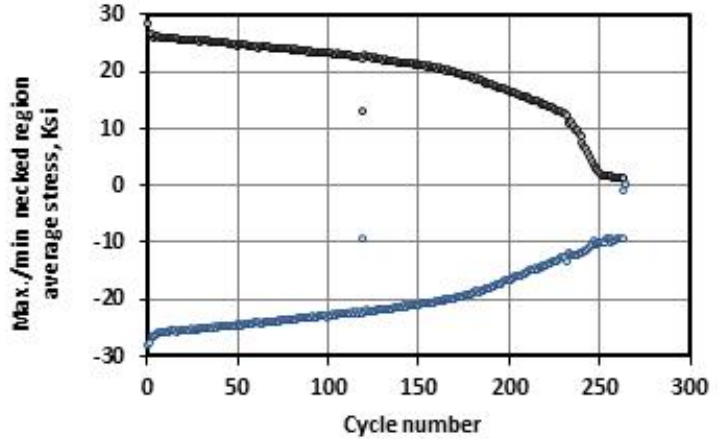

(b) Max/Min stresses

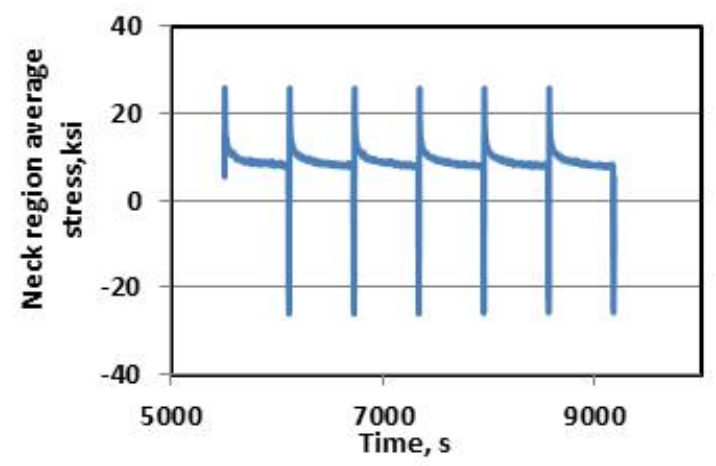

(d) Stress relaxation

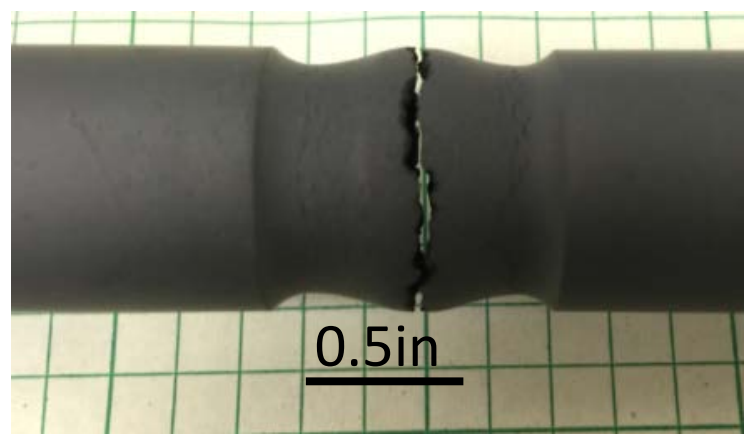

(f) failed specimen

Fig. 16. Test results for test Inc617-P02.

It is noted that these two pressurization tests experienced some experimental control issues such as furnace failure, pressure control, gas leak and large temperature gradient. Specifically, the intent for specimen INC617-P01 was to test with a small positive pressure of $2 \mathrm{psi}$, but there were occasionally pressure overshoots up to 50 psi during the test; and for specimen INC617-P02 with internal pressurization at $200 \mathrm{psi}$, it had a larger temperature difference of up to $12{ }^{\circ} \mathrm{C}$ across the controlled gage length with the necked test section at $959^{\circ} \mathrm{C}$ during most of the testing duration. Although these two tests were not perfectly controlled, the results can be used to verify the effect of internal pressure on the creepfatigue behavior of Alloy 617 under SMT condition. These control issues have been addressed. Additional testing over a range of temperatures, loading and hold time will be needed for further confirmation. 


\subsubsection{YSMT Test Results on Alloy 617}

Scoping YSMT tests with the new specimen geometry shown in Fig. 6 were first performed on SS316H because of the high machining cost of Alloy 617 specimens. YSMT controls and testing procedure were established using these scoping tests. A representation of these scoping tests was shown in Wang et al., 2015a.

A total of 6 YSMT tests were performed on Alloy 617 in this reporting period. The YSMT testing parameters are listed in Table 9 while the test results are summarized in Table 10. Plots of the measured strain range and maximum (tension) and minimum (compressive) stress as a function of cycle number, representative hysteresis loops, stress history, ratcheting strain and failed specimen for the these tests on Alloy 617 are presented in Figs. 17-21.

Table 9. YSMT parameters for Alloy 617.

\begin{tabular}{l|l|l|l|l|l}
\hline $\begin{array}{c}\text { Specimen } \\
\text { ID }\end{array}$ & $\begin{array}{c}\text { Necked test section } \\
\text { extens. output for 10 } \\
\text { volt }\end{array}$ & $\begin{array}{c}\text { Driver section } \\
\text { extens. output for } \\
\text { 10 volt }\end{array}$ & $\begin{array}{c}\text { Represented } \\
\text { driver length }\end{array}$ & $\begin{array}{c}\text { Loading } \\
\text { profile }\end{array}$ & $\begin{array}{c}\text { Test } \\
\text { Amplitude, } \\
\text { mils }\end{array}$ \\
\hline Inc617-102 & 15 mils & 6 mils & 1.875 & Fig. 8 & 4.6 \\
\hline Inc617-103 & $15 \mathrm{mils}$ & 6 mils & 1.875 & Fig. 8 & 2.3 \\
\hline Inc617-104 & $15 \mathrm{mils}$ & $6 \mathrm{mils}$ & 1.875 & Fig. 8 & 2.2 \\
\hline Inc617-105 & $15 \mathrm{mils}$ & $6 \mathrm{mils}$ & 1.875 & Fig. $10 \mathrm{a}$ & 2.3 \\
\hline Inc617-106 & $15 \mathrm{mils}$ & $6 \mathrm{mils}$ & 1.875 & Fig. $10 \mathrm{~b}$ & 2.3 \\
\hline
\end{tabular}

Note, gage length of the necked test section extensometer is 0.5in; gage length of the driver section extensometer is $0.75 \mathrm{in}$.

Table 10. YSMT results for Alloy 617.

\begin{tabular}{c|c|c|c|c|c}
\hline & $\begin{array}{c}\text { Calculated/Measured } \\
\text { Elastic strain range } \\
\text { in the necked section: }\end{array}$ & $\begin{array}{c}\text { \# of cycle } \\
\text { to failure }\end{array}$ & $\begin{array}{c}\text { Life time, } \\
\text { hrs }\end{array}$ & $\begin{array}{c}\text { Elastic follow } \\
\text { up, q }\end{array}$ & $\begin{array}{c}\text { Initial strain } \\
\text { range }\end{array}$ \\
\hline Inc617-102* & $0.632 / 0.593 \%$ & 90 & 15.3 & 2.6 & $1.5 \%$ \\
\hline Inc617-103 & $0.3 \% / 0.296 \%$ & 420 & 71.4 & 4.0 & $0.66 \%$ \\
\hline Inc617-104 & $0.3 \% / 0.296 \%$ & 380 & 64.6 & 3.76 & $0.63 \%$ \\
\hline Inc617-105 & $0.3 \% / 0.296 \%$ & 480 & 81.6 & 3.64 & $0.63 \%$ \\
\hline Inc617-106 & $0.3 \% / 0.296 \%$ & 215 & 74.1 & $\begin{array}{c}2.86 \text { tensile; } 2.53 \\
\text { compressive }\end{array}$ & $0.80 \%$ \\
\hline
\end{tabular}

YSMT specimen, Inc617-102, was tested at $950{ }^{\circ} \mathrm{C}$ with tension-hold time of $10 \mathrm{~min}$ with a large elastically calculated strain range of $0.6 \%$. The initial strain range was $1.5 \%$. This YSMT specimen had an elastic follow up factor of 2.6, and failed at about 90cycles.

An additional 5 YSMT tests were performed on Alloy 617 at $950{ }^{\circ} \mathrm{C}$ with the same elastically calculated strain range of $0.3 \%$ but with differently types of loading profile. Tests Inc617-103 and Inc617-104 used a tension-hold only loading profile. The two tests showed good consistency in terms of experimental controls and material behavior under YSMT testing condition. The tension hold specimens showed life time of $74.1 \mathrm{hr}$ with initial strain range of $0.66 \%$ for Inc617-103 and slightly shorter life time of $64.6 \mathrm{hr}$ with initial strain range of $0.63 \%$ for Inc617-104. All three tension-hold only tests showed compressive ratchetting behavior and barreled at the necked test section, consistent with the observation on SMT testing. 


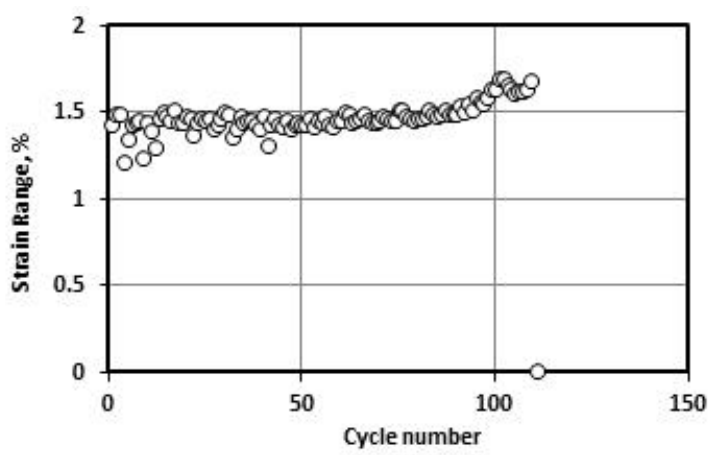

(a) Strain range

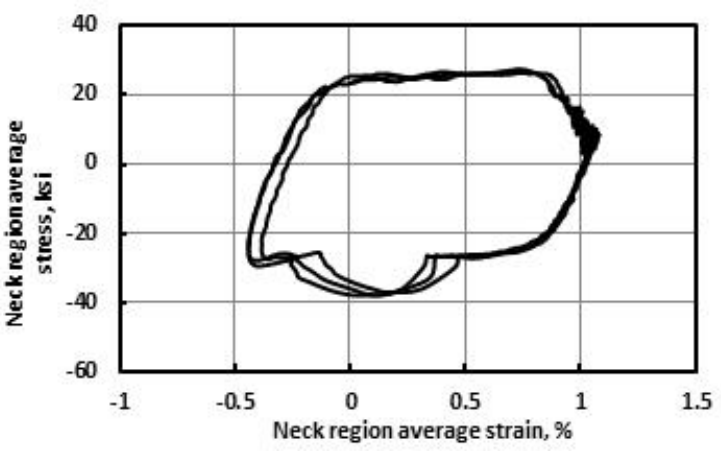

(c) Hysteresis Loop

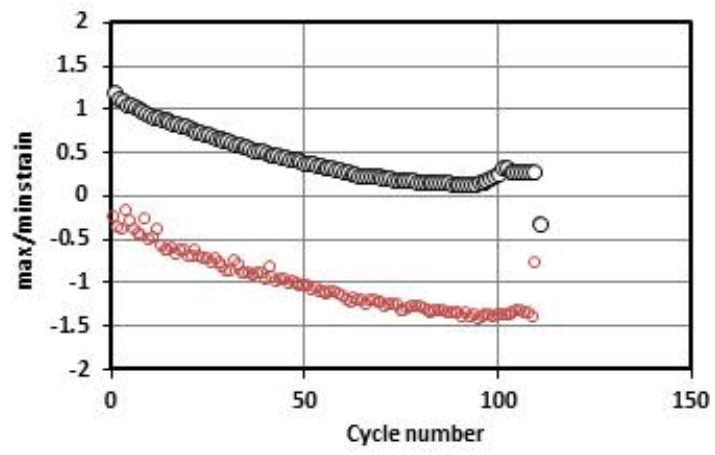

(e) ratcheting strain

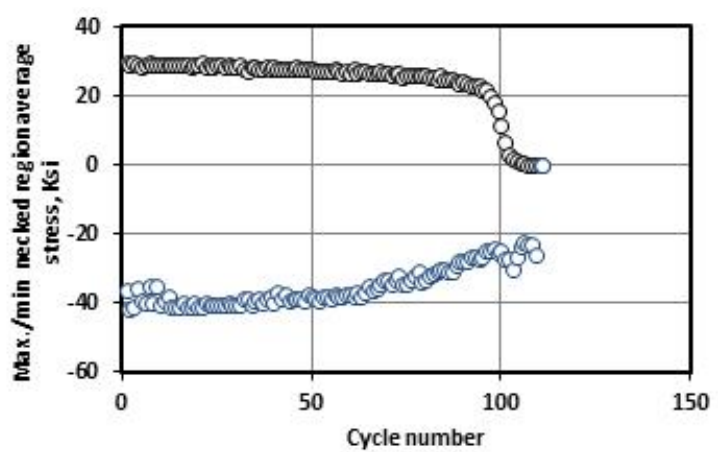

(b) Max/Min stresses

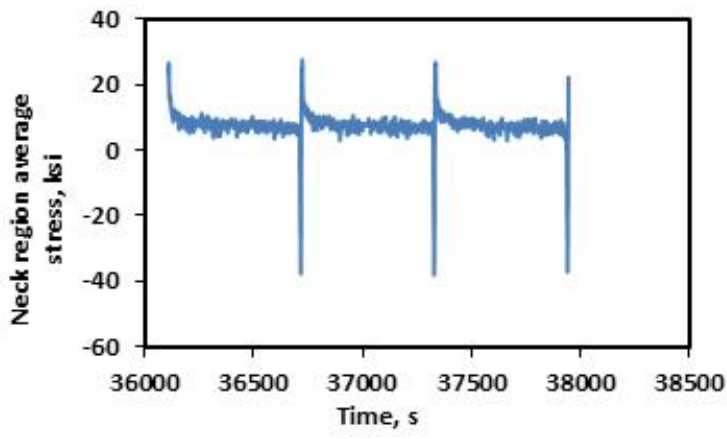

(d) Stress relaxation

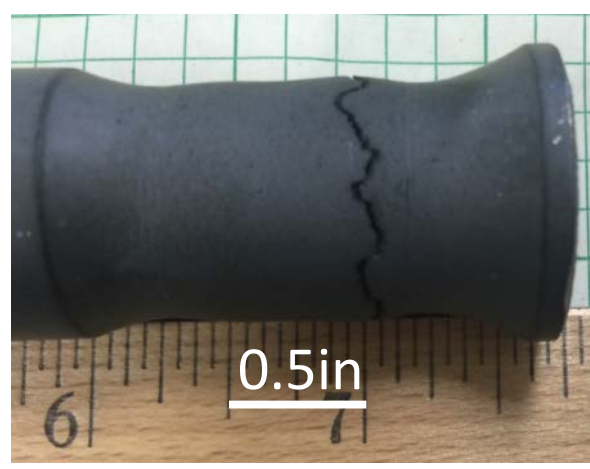

(f) failed specimen

Fig. 17. YSMT test results for Inc617-102 at $950^{\circ} \mathrm{C}$. 


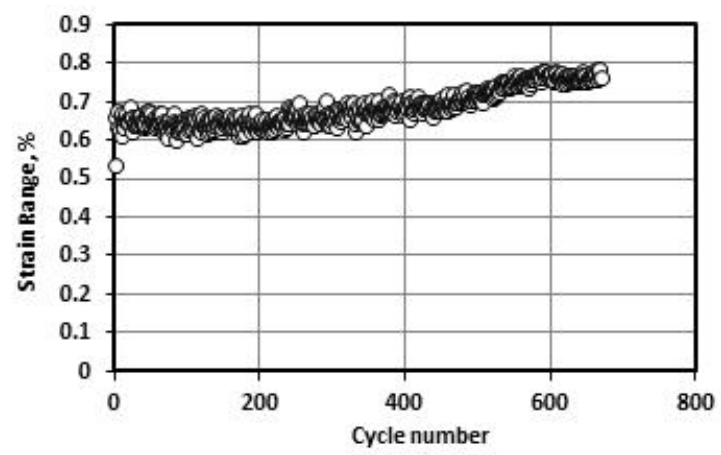

(a) Strain range

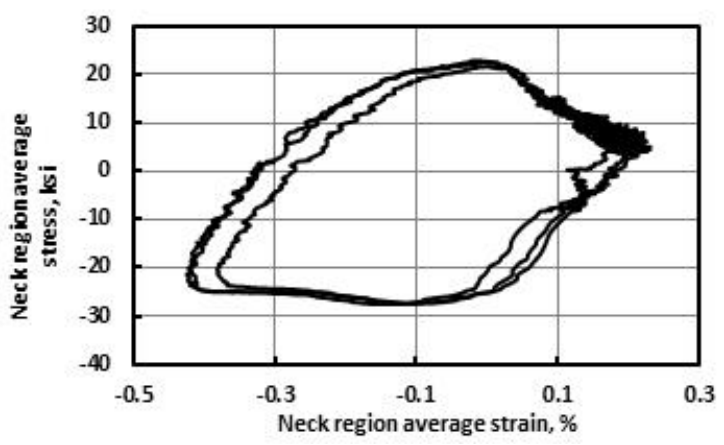

(c) Hysteresis Loop

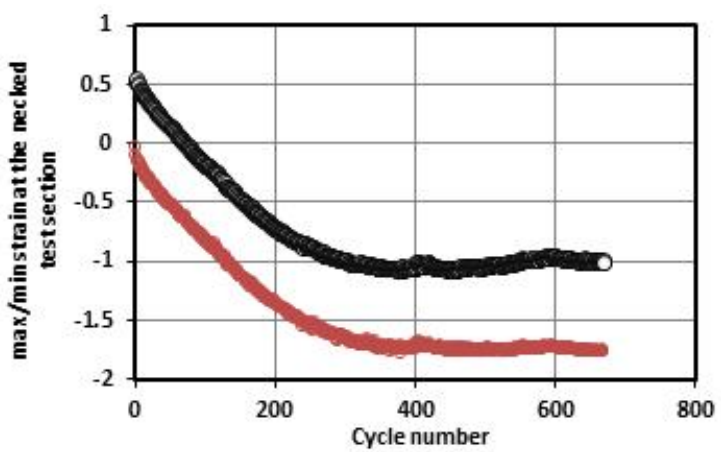

(e) ratcheting strain

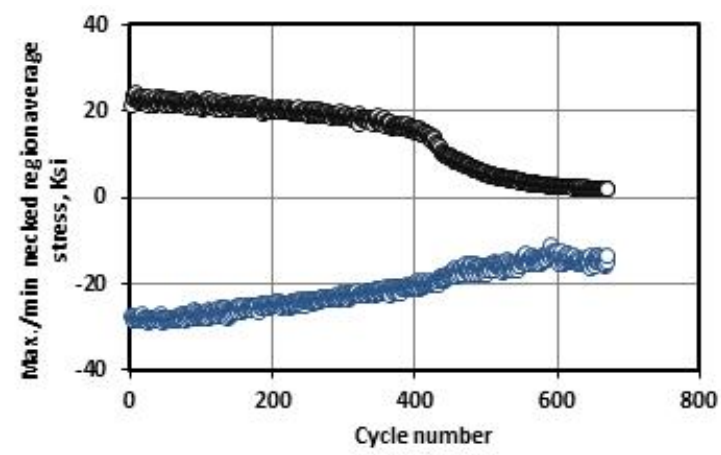

(b) Max/Min stresses

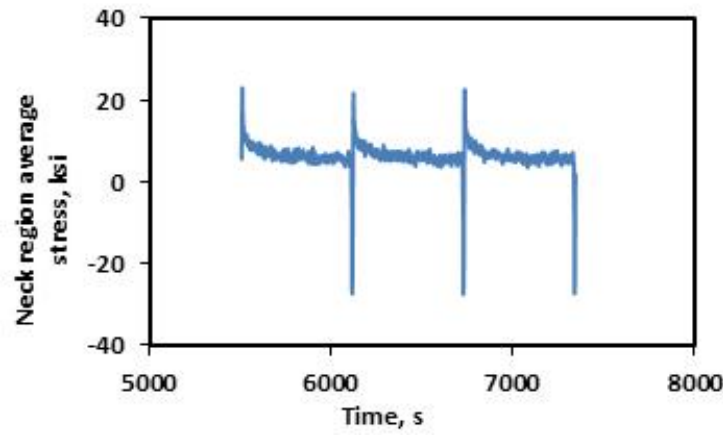

(d) Stress relaxation

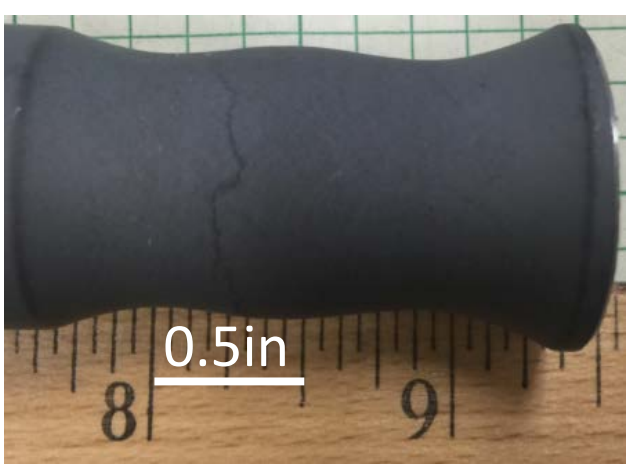

(f) failed specimen

Fig. 18. YSMT test results for Inc617-103 at $950^{\circ} \mathrm{C}$. 


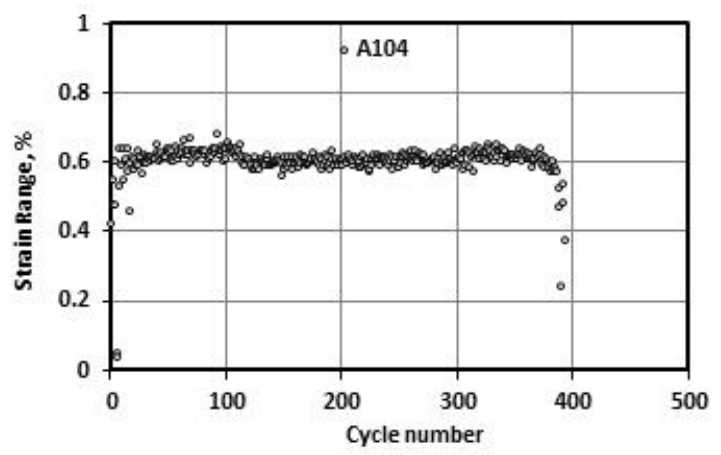

(a) Strain range

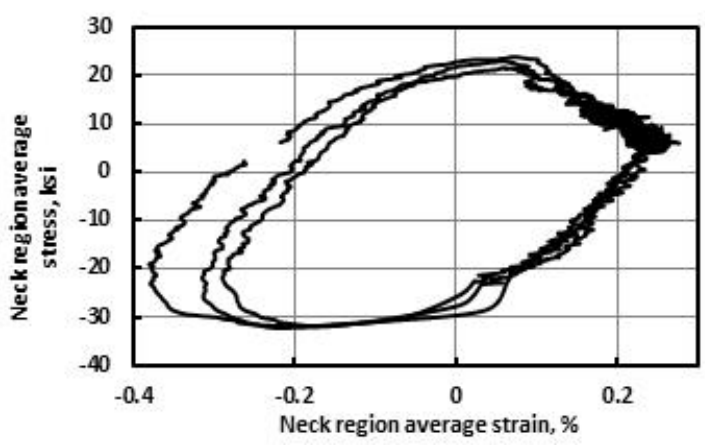

(c) Hysteresis Loop

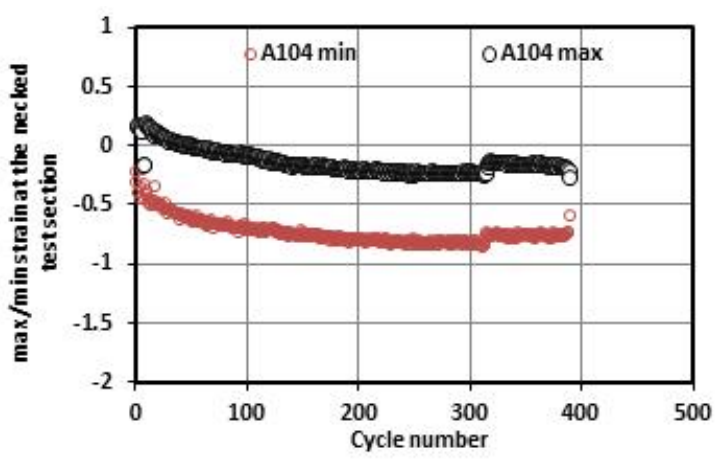

(e) ratcheting strain

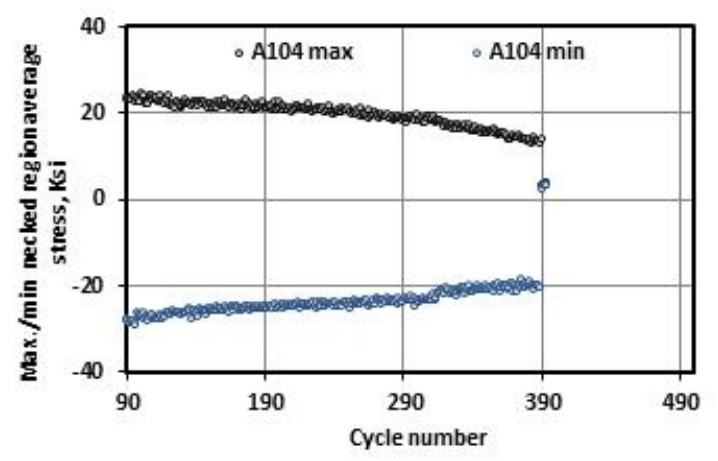

(b) Max/Min stresses

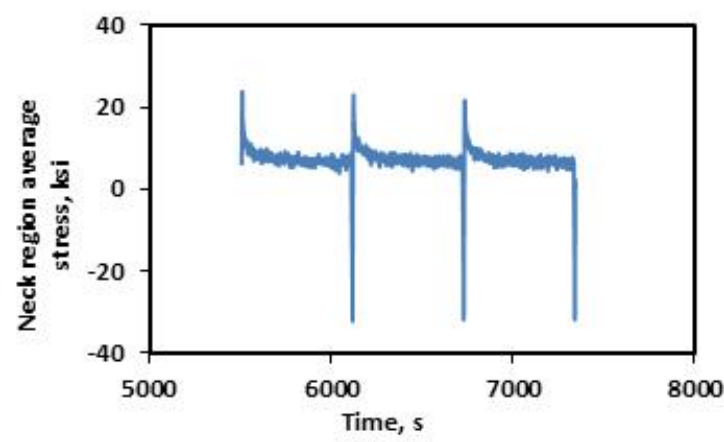

(d) Stress relaxation

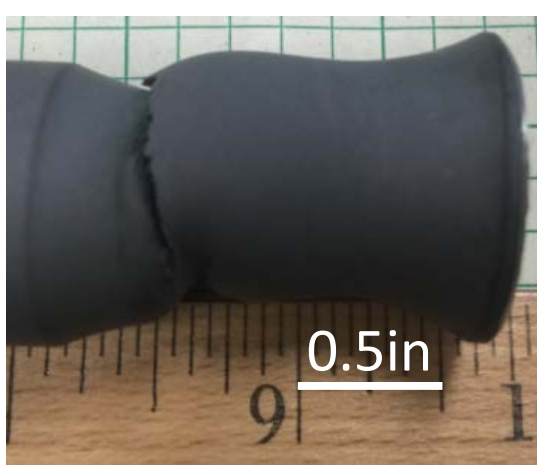

(f) failed specimen

Fig. 19. YSMT test results for Inc617-104 at $950^{\circ} \mathrm{C}$. 
Test on Inc617-105 used a compression-hold only loading profile and Inc617-106 used a combined tension-compression hold loading profile. Specimen Inc617-105 showed a lifetime of $74.8 \mathrm{hr}$. with initial strain range of $0.63 \%$ and specimen Inc617-106 showed a life time of about $74.1 \mathrm{hr}$. with an initial strain range of $0.80 \%$. Although the combined holding condition had larger tested strain range, it did not affect its life time. Inc617-105 showed tensile ratcheting behavior. Inc617-106 had the minimum ratcheting among the 6 YSMT tests.

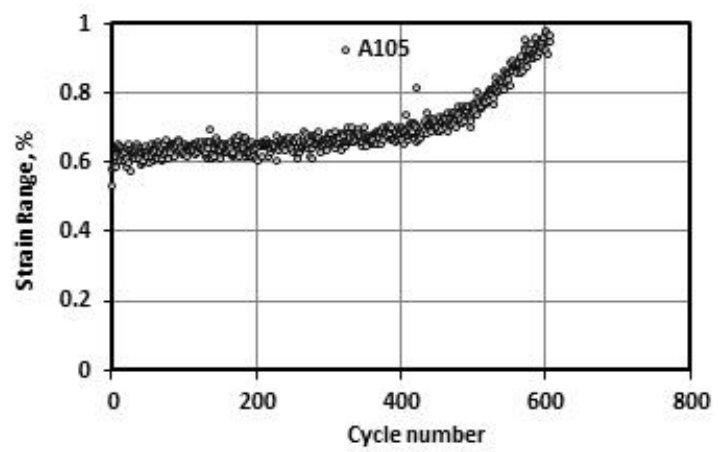

(a) Strain range

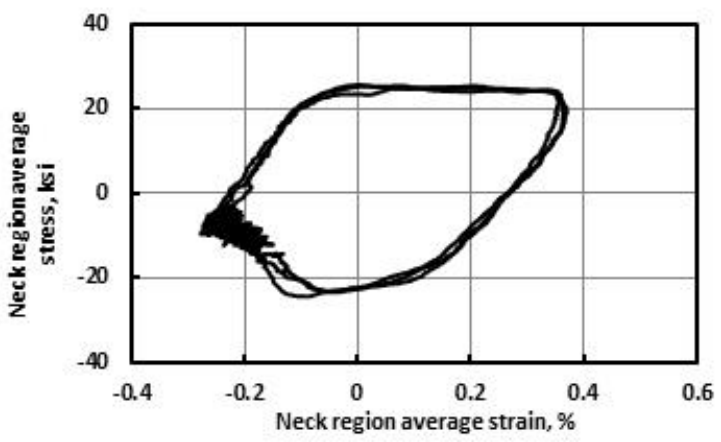

(c) Hysteresis Loop

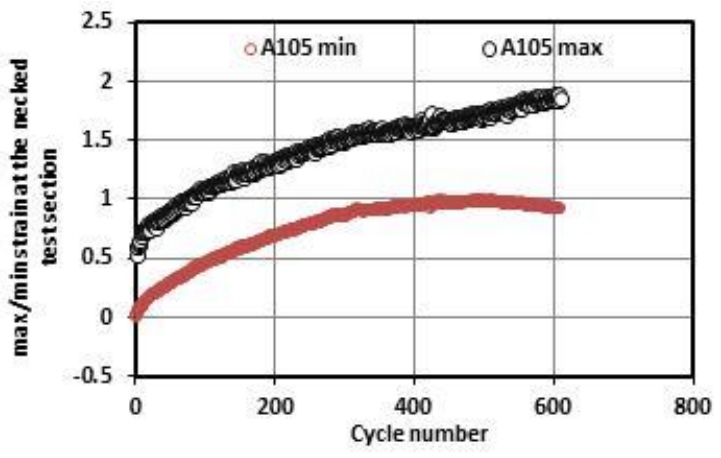

(e) ratcheting strain

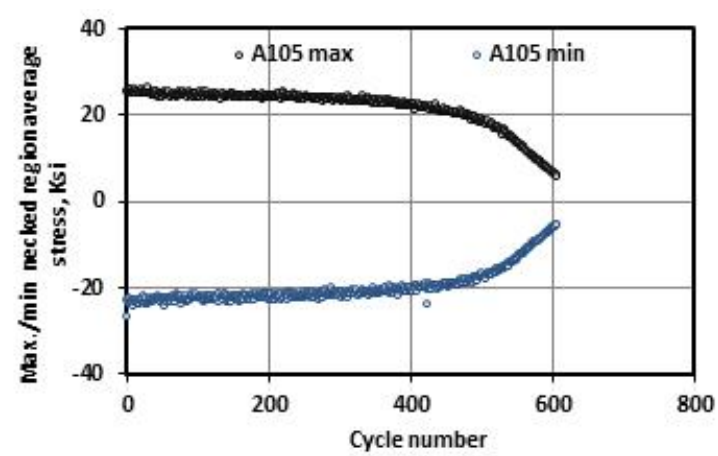

(b) Max/Min stresses

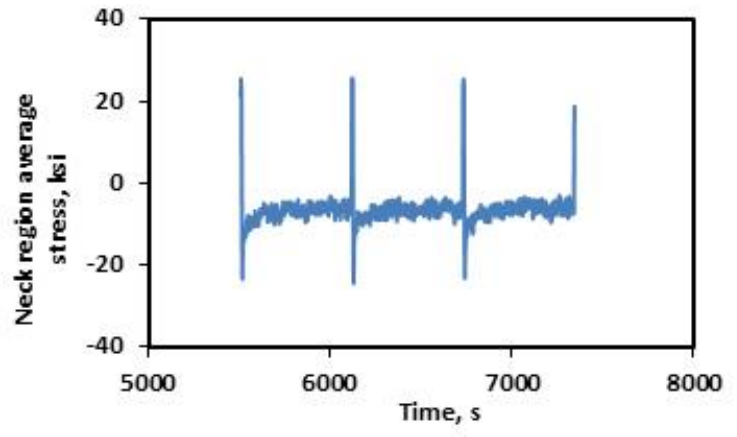

(d) Stress relaxation

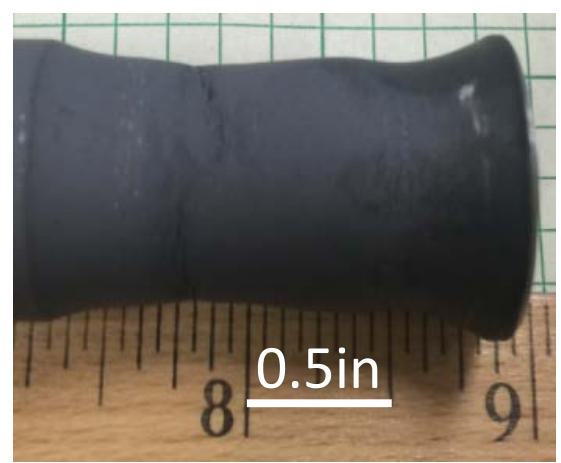

(f) failed specimen

Fig. 20. YSMT test results for Inc617-105 at $950^{\circ} \mathrm{C}$. 
It is important to notice that buckling was not observed for YSMT tests, confirming successfully designed YSMT specimen geometry.

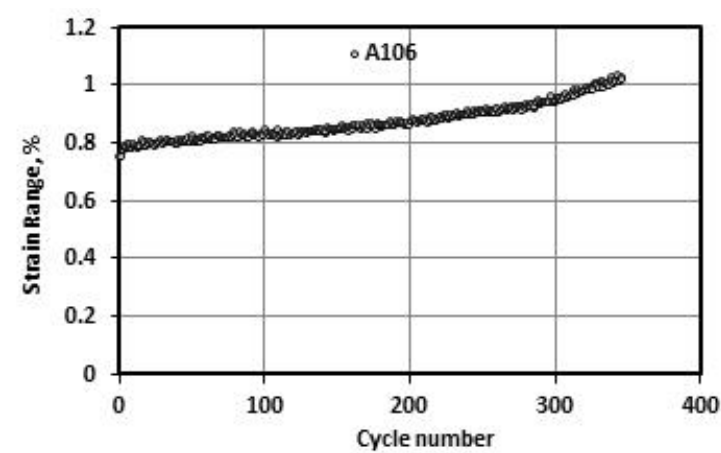

(a) Strain range

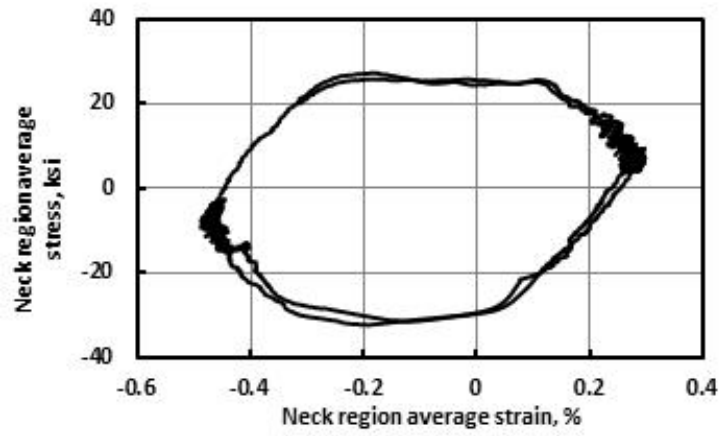

(c) Hysteresis Loop

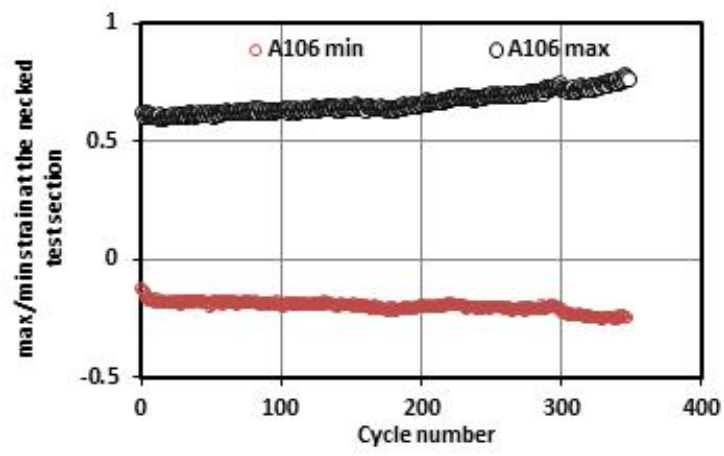

(e) ratcheting strain

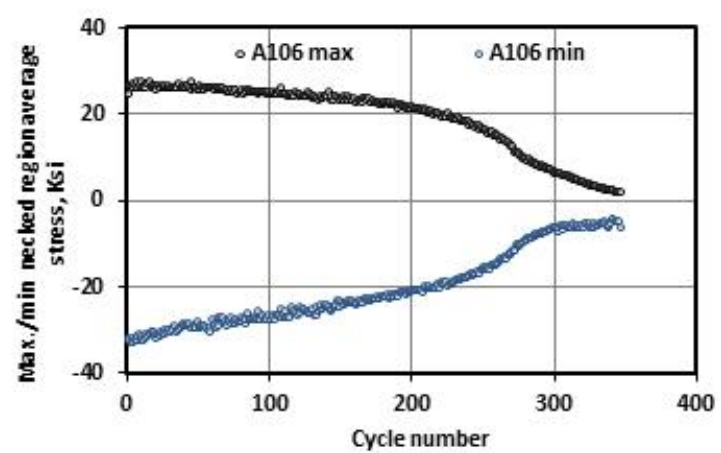

(b) Max/Min stresses

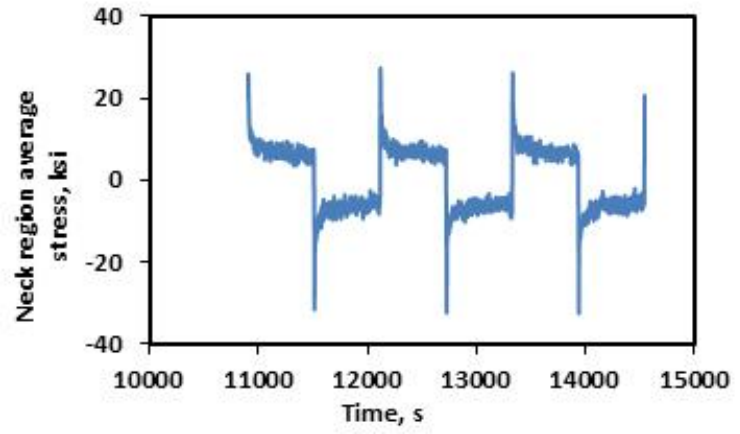

(d) Stress relaxation

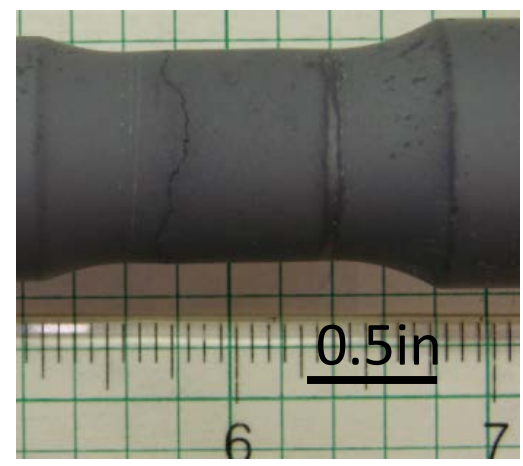

(f) failed specimen

Fig. 21. YSMT test results for Inc617-106 at $950^{\circ} \mathrm{C}$.

\subsection{TWO-BAR THERMAL RACHETING}

\subsubsection{Previous Two-bar Thermal Ratcheting Test Results}

In the earlier reports by Wang et al. (2013b, 2014b, 2015b), two-bar thermal ratcheting tests were

performed on SS316H at temperature range of $515-815^{\circ} \mathrm{C}$ and on Alloy 617 at temperature ranges of 650 
$-950^{\circ} \mathrm{C}, 500-800^{\circ} \mathrm{C}$ and a few at $350-650^{\circ} \mathrm{C}$. Two-bar thermal ratcheting tests with combinations of applied mean stresses, transient temperature difference and heating and cooling rates were performed at heating and cooling rates of $30^{\circ} \mathrm{C} / \mathrm{min}$ that are comparable to a strain rate of $10^{-5} / \mathrm{sec}$. Tests were performed following the temperature profile shown in Fig. 22.

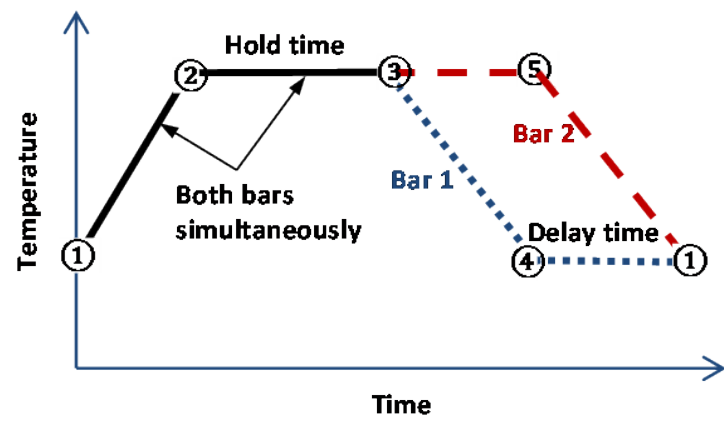

Fig. 22. Temperature vs. time histogram for two-bar thermal ratcheting experiments.

The two-bar thermal ratcheting test results from shorter test periods were extrapolated to obtain the ratcheting strain at $200 \mathrm{hr}$. and these results are presented in Figs. 27-30 along with strain limits predictions. The suite of tests on SS316H at a temperature range of $515^{\circ} \mathrm{C}$ to $815^{\circ} \mathrm{C}$ as shown in Fig. 30 resembled the results from the tests on Alloy 617 at $650^{\circ} \mathrm{C}$ to $950^{\circ} \mathrm{C}$ as shown in Fig. 23. Note the similarity between these results for SS316H and for Alloy 617 at a maximum temperature of $950^{\circ} \mathrm{C}$. In both cases there is a narrow stovepipe representing the predicted 1\% strain limit from the EPP strain limit code case. And, in both cases, the test results at a high thermal stress range represented by the 10 minute time delay do not agree with the code case prediction. This demonstrates that the restriction of skeletal structures developed for Alloy 617 would be expected to apply to SS316H and other similar materials

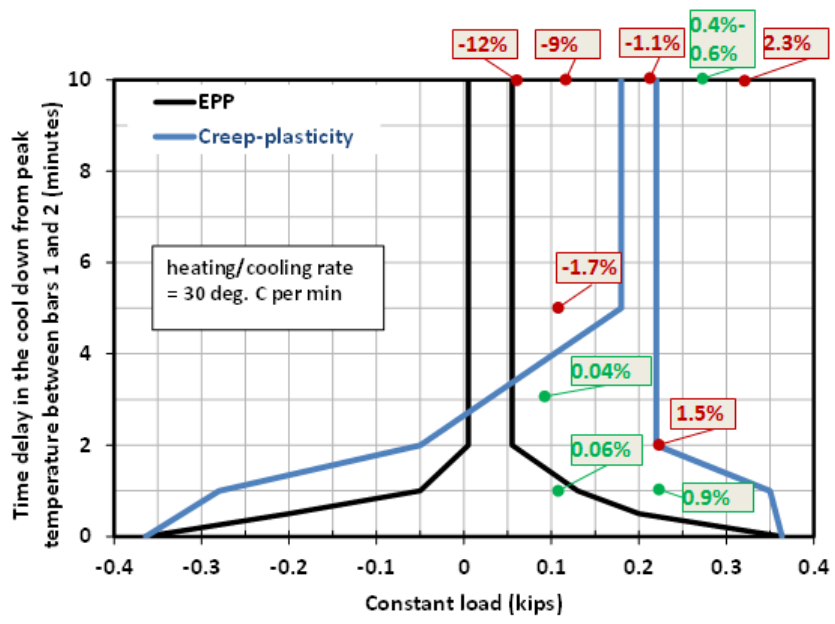

Fig. 23. Two bar test data with $1 \%$ design envelope predictions from the strain limits code case and inelastic analysis (Alloy 617 with testing temperature range of $650^{\circ} \mathrm{C}$ to $950^{\circ} \mathrm{C}$ ).

Interestingly, the suite of tests on Alloy 617 at the lower temperature range of $500^{\circ} \mathrm{C}$ to $800^{\circ} \mathrm{C}$ as shown in Fig. 28 showed good agreement with the proposed EPP strain limit rules with a much wider band of 
applied load that exhibited minimal ratcheting. The four tests conducted at the lower temperature range of $350^{\circ} \mathrm{C}$ to $650^{\circ} \mathrm{C}$ as shown in Fig. 29 showed no ratcheting.

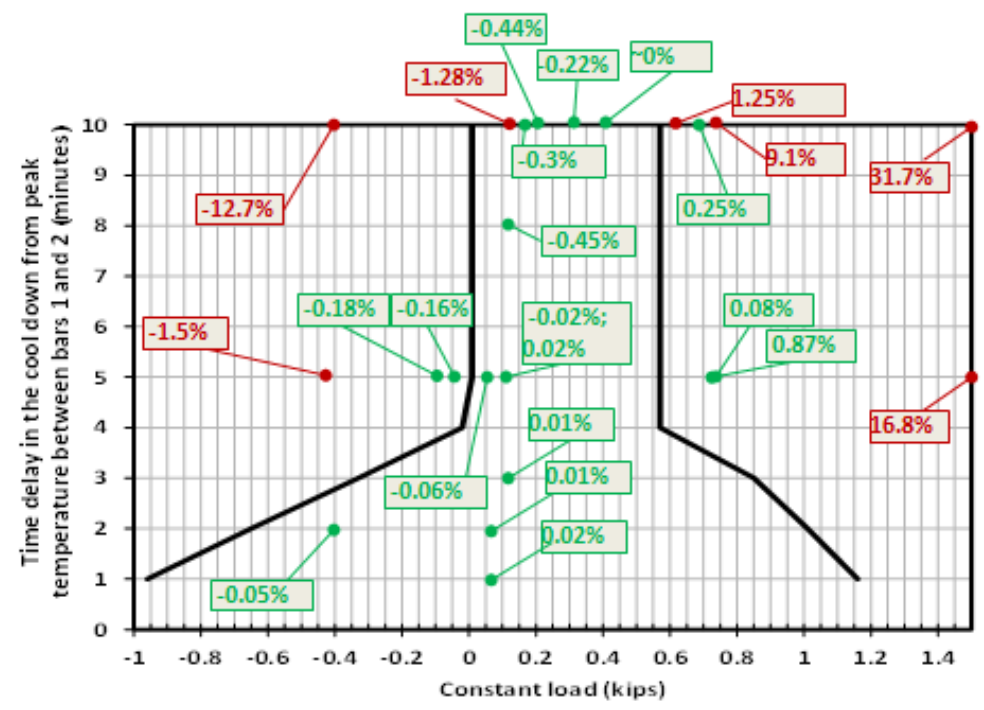

Fig. 24. Two bar test data with $1 \%$ design envelope predictions from the strain limits code case (Alloy 617 with testing temperature range of $500^{\circ} \mathrm{C}$ to $800^{\circ} \mathrm{C}$ ).

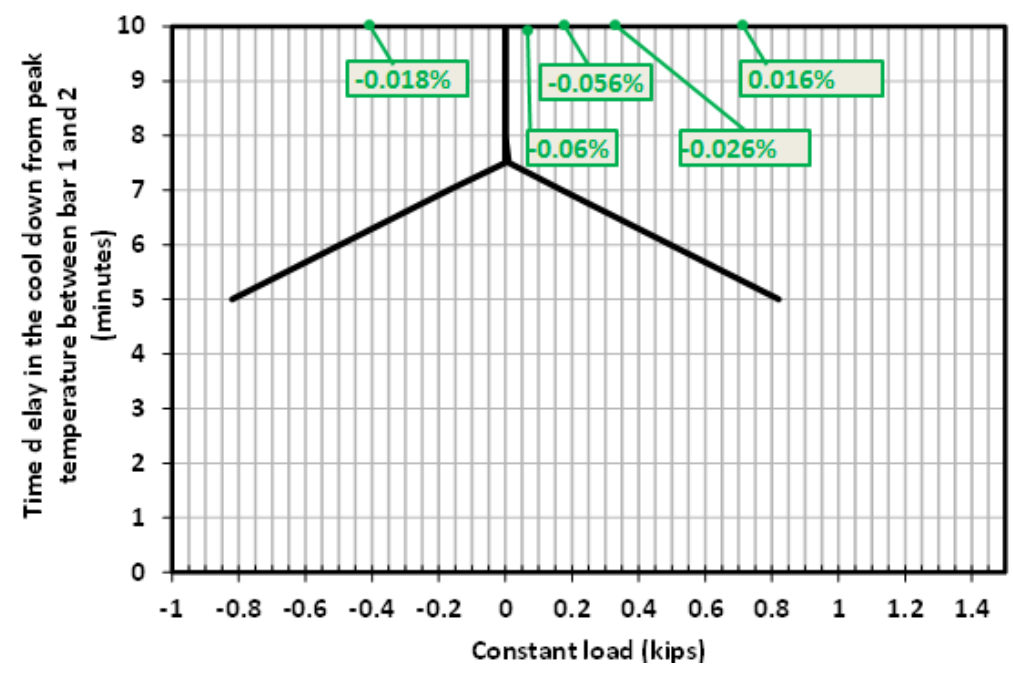

Fig. 25. Two bar test data with $1 \%$ design envelope predictions from the strain limits code case (Alloy 617 with testing temperature range of $350^{\circ} \mathrm{C}$ to $650^{\circ} \mathrm{C}$ ). 


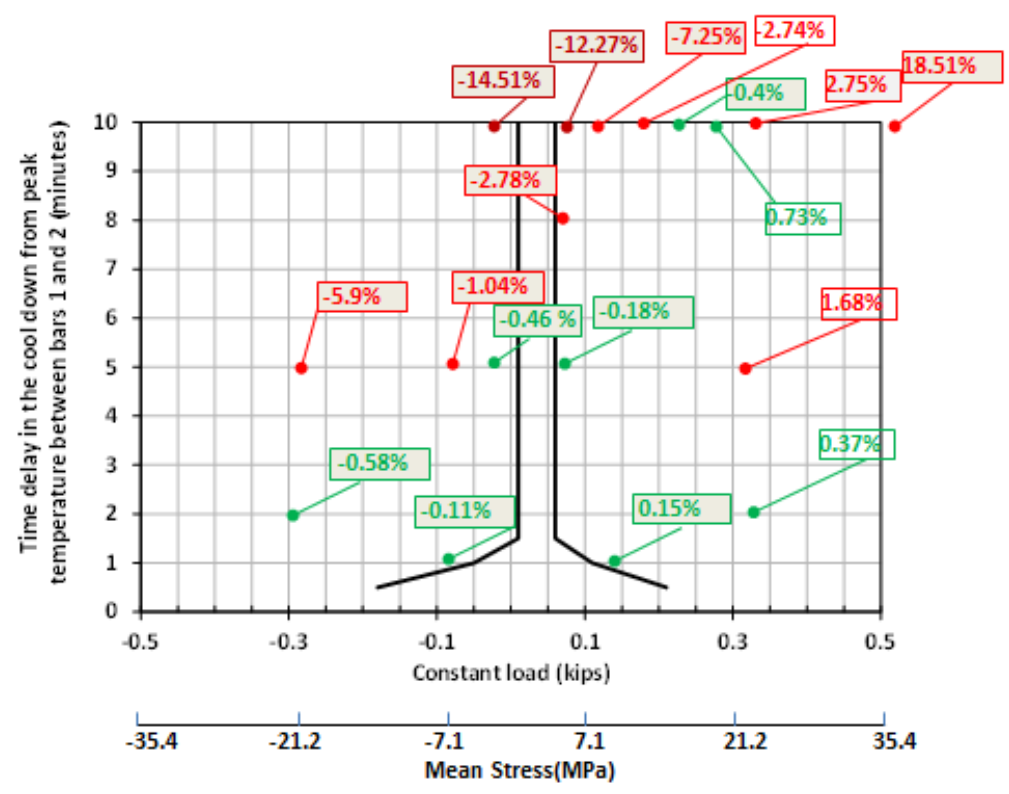

Fig. 26. Two bar test data with $1 \%$ design envelope predictions from the strain limits code case and inelastic analysis (SS316H with testing temperature range of $515^{\circ} \mathrm{C}$ to $815^{\circ} \mathrm{C}$ ).

\subsubsection{Two-bar Thermal Ratcheting of SS316H at Temperature Range of $250^{\circ} \mathrm{C}$ to $550{ }^{\circ} \mathrm{C}$}

In this reporting period, two-bar thermal ratcheting tests were performed on SS316H to assess the material response to cyclic thermal loading under two-bar testing conditions at a lower temperature range of $250-550^{\circ} \mathrm{C}$. This temperature range is much lower than the maximum temperature of $815^{\circ} \mathrm{C}$ for which allowable stress values are provided in Subsection HBB (formerly NH). The experiments were performed on the same set of specimens with sequential test number of T25-1, T25-2, T25-3, T25-4, T25-5, T25-6 and T25-7. The ratcheting rate was large for test T25-7 and the test failed after 16 complete cycles.

Consistent with the preceding work by Wang et al. (2013b, 2014b, nbb2015b), the ratcheting strain is defined as the difference in the mechanical strain at a time point in a cycle and that at the same time point in the reference cycle. The mechanical strain is the sum of the elastic strain and inelastic strain, and it can be extracted from the test data by subtracting the thermal expansion from the total strain. When the same reference point in the thermal cycle is selected, the amount of ratcheting strain calculated based on the total strain is the same as that calculated based on mechanical strain. The experimental results show that the first several cycles from one testing condition to another is significantly different and therefore is ignored in the ratcheting strain extrapolations. In this study, a reference cycle is used for each test. The ratcheting behavior is steady and the ratcheting rate is near constant from the reference cycle forward. The ratcheting strains were calculated from the maximum total strains of each cycle, and they were approximately the same values when calculated based on the minimum strains. Results from shorter test periods were extrapolated to obtain the ratcheting strain at $200 \mathrm{hr}$ to provide information to our parallel theoretical studies on strain limits. The test parameters and the test results for all the testing conditions are summarized in Table 11.

Shown below in Fig.27 is a plot of the above tabulated test results extended to 200hr based on the measured the ratcheting strain rate. Among all the test conditions but one large compressive total load of 1500lbs (T25-7), the ratcheting strains in $200 \mathrm{hr}$. were found to be less than $1 \%$ strain limits. This is a much wider applied primary load range to result in less than $1 \%$ strains than that for high testing temperature shown in Fig.26. These teste results are provided for verification of EPP strain limits analysis. 
Table 11. Summary of the two-bar thermal ratcheting experiments on SS316H for temperature range of $250{ }^{\circ} \mathrm{C}$ to $550^{\circ} \mathrm{C}$.

\begin{tabular}{l|l|l|l|l|l|l|l}
\hline Test No. & $\mathbf{T 2 5 - 1}$ & $\mathbf{T 2 5}-2$ & $\mathbf{T 2 5}-\mathbf{3}$ & $\mathbf{T 2 5 - 4}$ & $\mathbf{T 2 5}-\mathbf{5}$ & $\mathbf{T 2 5 - 6}$ & $\mathbf{T 2 5 - 7}$ \\
\hline $\begin{array}{l}\text { Applied mean } \\
\text { stress, MPa }\end{array}$ & $3.6 \pm 0.6$ & $49.3 \pm 0.5$ & $-35 \pm 0.5$ & $70.8 \pm 0.6$ & $-70.6 \pm 0.5$ & $84.3 \pm 0.6$ & $-104.4 \pm 14.6$ \\
\hline Time delay, min & 10 & 10 & 10 & 10 & 10 & 10 & 10 \\
\hline $\begin{array}{l}\text { Total No. of } \\
\text { cycles tested }\end{array}$ & 34 & 48 & 32 & 32 & 50 & 31 & 16 \\
\hline $\begin{array}{l}\text { Ratcheting rate } \\
\text { (per cycle), \% }\end{array}$ & -0.0021 & 0.0016 & -0.0036 & 0.0076 & -0.0084 & 0.008 & -0.065 \\
\hline $\begin{array}{l}\text { Initial stress on } \\
\text { Bar 1, MPa }\end{array}$ & 0.6 & -109.3 & 127.9 & -84.7 & -213.5 & -62.5 & -227.5 \\
\hline $\begin{array}{l}\text { Initial stress on } \\
\text { Bar 2, MPa }\end{array}$ & 10.9 & 209.1 & -35.3 & 225.9 & 71.5 & 230.2 & 15.3 \\
\hline $\begin{array}{l}\text { Initial residual } \\
\text { total strain, \% }\end{array}$ & 0 & -0.1 & 0.15 & -0.16 & 0.39 & -0.57 & 0.058 \\
\hline $\begin{array}{l}\text { Reference cycle } \\
\text { No. }\end{array}$ & 10 & 10 & 10 & 10 & 10 & 10 & 10 \\
\hline $\begin{array}{l}\text { Min. strain of } \\
\text { the reference } \\
\text { cycle, \% }\end{array}$ & -0.105 & 0.148 & -0.185 & 0.329 & -0.387 & -0.0062 & -1.05 \\
\hline $\begin{array}{l}\text { Stress range per } \\
\text { cycle for Bar 1, } \\
\text { MPa }\end{array}$ & $407.0 \pm 6.7$ & $429.5 \pm 9.1$ & $431.9 \pm 9.9$ & $436.3 \pm 16.7$ & $445.0 \pm 18.3$ & $444.5 \pm 20.1$ & $430.3 \pm 34.0$ \\
\hline $\begin{array}{l}\text { Stress range per } \\
\text { cycle for Bar 2, } \\
\text { MPa }\end{array}$ & $406.4 \pm 7.2$ & $418.9 \pm 8.8$ & $435.6 \pm 16.4$ & $435.6 \pm 16.4$ & $444.5 \pm 20.5$ & $443.6 \pm 20.2$ & $429.5 \pm 34.2$ \\
\hline
\end{tabular}

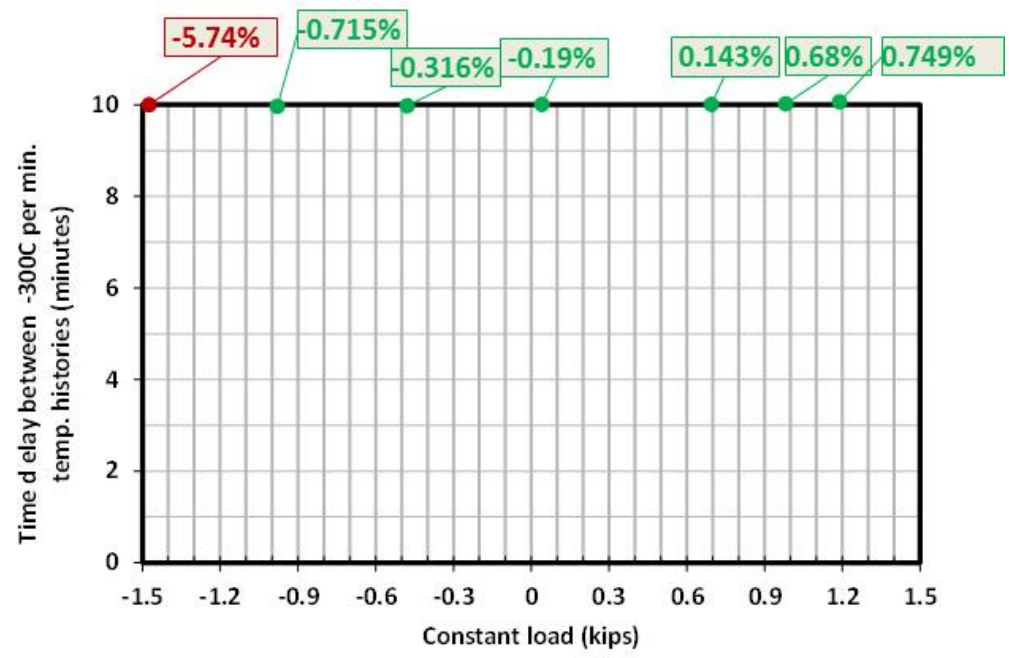

Fig. 27. Two bar test data for SS316H with testing temperature range of $250-550^{\circ} \mathrm{C}$. 


\section{SUMMARY}

The concept of Elastic-Perfectly Plastic (EPP) combined integrated creep-fatigue damage evaluation approach is presented. The goal of the proposed approach is to combine the advantage of the EPP strain limit methodology, that avoids stress classification, with the advantage of the Simplified Model Test (SMT) method for evaluating creep-fatigue damage without deconstructing the cyclic history into separate fatigue and creep damage evaluations. The EPP methodology for strain is based on the use of a pseudo yield stress that limits creep and plastic strain accumulation and intrinsically reflects the stress and strain redistribution currently based on the use of stress classification procedures. The resulting strain ranges are then assessed for combined creep and fatigue damage using the SMT approach. In this approach, the enhanced damage resulting from strain redistribution and slowed stress relaxation due to follow up effects is accommodated in the design of the test specimen, sized to bound redistribution effects in typical components. A path forward to merge these methodologies was identified along with the anticipated problems, facilitating assumptions, and required steps and test data needed to verify their applicability.

\subsection{LOWER TEMPERATURE TEST RESULTS}

Experimental SMT results from lower temperature testing are of great interest for verification of the design rules. SMT test \# 27 was performed at $650{ }^{\circ} \mathrm{C}$ with an elastically calculated strain range of $0.4 \%$ at the necked test section on a Type 1 SMT specimen with tension-hold only loading profile. The test had $\sim 5200$ cycles to failure. The total ratcheting strain for the test section was found to be less than $1 \%$. It is noted that this test had minor control issues throughout the long test period, but the test data is of value for reference for this low temperature test condition.

\subsection{COMPRESSION HOLD OR COMBINED TENSILE-COMPRESSION HOLD TESTS FOR TYPE 1 SMT CONFIGURATION}

Compared to the tension-hold only test results, the compression-hold only condition test failed in a slightly larger number of cycles and the combined tension-compression hold condition test failed in a similar number of complete cycles. However, since the total hold time per complete cycle, 10 minutes each in tension and compression, is twice the hold time tension or compression-hold only, the total test duration of the combined tension-compression hold test was about twice the duration of the tension or compression-hold only test. Interestingly, the overall ratcheting was less than $1 \%$ with combined tensioncompression deformation.

\subsection{PRESSURIZATION TEST RESULTS}

Two tests showed similar initial strain range and 220 cycles to failure, one test at a nominal 2 psi and the other at 200psi. Both specimens showed an elastic follow up factor of $\sim 3.8$. The ratcheting behaviors of the two specimens were both toward compressive direction and the ratcheting rate was similar. Both specimens failed at the center of the necked test section with significant amount of barreling. Thus, it can be concluded that the 200 psi internal pressure did not make much difference in terms of the specimen behavior for these two tests. This is an important initial finding as it supports the assumption that the SMT design curves will be independent of primary load. Additional testing over a range of temperatures, loading and hold time will be needed for further confirmation.

\subsection{YSMT TEST RESULTS}

Total of 5 Alloy 617 YSMT tubular specimens were tested at 950C with the same elastically calculated strain range of $0.3 \%$. Two specimens were tested with a tension hold time of $10 \mathrm{mins}$, one had a 
compression hold time of 10min and one specimen had combined tension hold of 10min and compression hold of 10min. The results were in general agreement within experimental tolerances with the above summarized results for the Type 1 SMT solid bar specimens

\subsection{TWO-BAR THERMAL RATCHETING OF SS316H AT TEMPERATURE RANGE OF $250^{\circ} \mathrm{C}$ TO $550^{\circ} \mathrm{C}$}

In this reporting period, two-bar thermal ratcheting tests were performed on SS316H to assess the material response to cyclic thermal loading under two-bar testing conditions at a lower temperature range of $250-550^{\circ} \mathrm{C}$. For all the test conditions except one large compressive total load of $1500 \mathrm{lbs}$, the extrapolated ratcheting strains in 200 hrs were found to be less than $1 \%$ strain limits. This is a much wider applied primary load range to result in less than $1 \%$ strains than that for the higher prior testing temperature range of $515^{\circ} \mathrm{C}$ to $815^{\circ} \mathrm{C}$. 


\section{REFERENCES}

1. Jetter, R. I., (1998), “An Alternate Approach to Evaluation of Creep-Fatigue Damage for High Temperature Structural Design Criteria,” PVP-Vol. 5 Fatigue, Fracture and High Temperature Design Methods in Pressure Vessel and Piping, Book No. H01146 - 1998, American Society of Mechanical Engineers Press, New York, New York.

2. Wang, Y., Jetter, R .I. and Sham, T.-L, (2013a), "Report on Alloy 617 SMT Creep-Fatigue Scoping Test”, ORNL/LTR-2013/600, Oak Ridge National Laboratory, Oak Ridge, TN.

3. Wang, Y., Sham, T.-L, and Jetter, R .I., (2013b), "Progress report on the development of test procedure for the two-bar thermal ratcheting experiment for Alloy 617,” ORNL/TM-2013/318, Oak Ridge National Laboratory, Oak Ridge, TN.

4. Wang, Y., Jetter, R .I. and Sham, T.-L, (2014a), “Application of Simplified Model Tests to Alloy 617 Creep-Fatigue Damage Evaluation”, ORNL/TM-2014/360, Oak Ridge National Laboratory, Oak Ridge, TN.

5. Wang, Y., Jetter, R .I. and Sham, T.-L, (2014b), “Application of Combined Sustained and Cyclic Loading Test Results to Alloy 617 Elevated Temperature Design Criteria”, ORNL/TM-2014/294, Oak Ridge National Laboratory, Oak Ridge, TN.

6. Wang, Y., Jetter, R. I., Baird, S. T., Pu, C. and Sham, T.-L. (2015a), “Simplified Model Test (SMT) creep-fatigue testing” ORNL/TM-2015/300, Oak Ridge National Laboratory, Oak Ridge, TN.

7. Wang, Y., Jetter, R. I., Baird, S. T., Pu, C. and Sham, T.-L. (2015b), "Report on FY15 Two-Bar Thermal Ratcheting Test Results” ORNL/TM-2015/284, Oak Ridge National Laboratory, Oak Ridge, TN. 


\section{ELECTRONIC DISTRIBUTION}

$\begin{array}{lll}\text { Name } & \text { Affiliation } & \text { Email } \\ \text { Carroll, L. } & \text { INL } & \text { Laura.Carroll@INL.gov } \\ \text { Corwin, W. } & \text { DOE } & \text { william.corwin@nuclear.energy.gov } \\ \text { Hill, R.N. } & \text { ANL } & \text { bobhill@anl.gov } \\ \text { Jetter, R.I. } & \text { Consultant } & \text { bjetter@sbcglobal.net } \\ \text { Lara-Curzio, E. } & \text { ORNL } & \text { laracurzioe@ornl.gov } \\ \text { Li, M. } & \text { ANL } & \text { mli@anl.gov } \\ \text { Petti, D. } & \text { INL } & \text { David.Petti@inl.gov } \\ \text { Pu, C. } & \text { University of Tennessee } & \text { cpu@utk.edu } \\ \text { Sham, T.-L. } & \text { ORNL } & \text { ssham@anl.gov } \\ \text { Sink, C. } & \text { DOE } & \text { carl.sink@nuclear.energy.gov } \\ \text { Wang, H. } & \text { ORNL } & \text { wangh@ornl.gov } \\ \text { Wang, Y. } & \text { ORNL } & \text { wangy3@ornl.gov } \\ \text { Wright, R.N. } & \text { INL } & \text { richard.wright@inl.gov } \\ \text { ORNL Office of Technical } & & \\ \text { Information and Classification } & & \end{array}$

